University of Nebraska - Lincoln

DigitalCommons@University of Nebraska - Lincoln

\title{
Modeling of Carbon Dioxide Transport and Production in Soil 2. Parameter Selection, Sensitivity Analysis, and Comparison of Model Predictions to Field Data
}

\author{
Donald L. Suarez \\ USDA-ARS, donald.suarez@ars.usda.gov \\ Jiří Šimůnek \\ USDA-ARS
}

Follow this and additional works at: https://digitalcommons.unl.edu/usdaarsfacpub

Part of the Agricultural Science Commons

Suarez, Donald L. and Šimůnek, Jiří, "Modeling of Carbon Dioxide Transport and Production in Soil 2. Parameter Selection, Sensitivity Analysis, and Comparison of Model Predictions to Field Data" (1993). Publications from USDA-ARS / UNL Faculty. 505.

https://digitalcommons.unl.edu/usdaarsfacpub/505

This Article is brought to you for free and open access by the U.S. Department of Agriculture: Agricultural Research Service, Lincoln, Nebraska at DigitalCommons@University of Nebraska - Lincoln. It has been accepted for inclusion in Publications from USDA-ARS / UNL Faculty by an authorized administrator of DigitalCommons@University of Nebraska - Lincoln. 


\title{
Modeling of Carbon Dioxide Transport and Production in Soil 2. Parameter Selection, Sensitivity Analysis, and Comparison of Model Predictions to Field Data
}

\author{
DONALD L. SUAREZ AND JiŘí ŠIMƯNEK ${ }^{1}$ \\ U.S. Salinity Laboratory, Agricultural Research Service, U.S. Department of Agriculture, Riverside, California
}

\begin{abstract}
In paper 1 of this two-paper series (Šminek and Suarez, this issue) we presented a description of the numerical model, SOILCO2, for $\mathrm{CO}_{2}$ transport and production in the unsaturated zone. In paper 2 the model sensitivity to various parameters is evaluated by both steady state and transient simulations, with a range in the parameter values typically found under field conditions. We also select parameter values for optimal plant and microbial $\mathrm{CO}_{2}$ production and production dependence on temperature, water content, osmotic potential and gas composition for plant and microbial respiration, all based on literature review. The predictive capabilities of the SOILCO2 model are evaluated by comparing model simulations to published field data from Missouri for three different crops and two growing seasons under transient conditions as well as a data set collected in Riverside, California, under relatively constant water content at depth. The model provided good prediction of the $\mathrm{CO}_{2}$ flux to the atmosphere as well as the concentrations in the root zone for all data sets.
\end{abstract}

\section{INTRODUCTION}

The wide interest in soil gas composition is reflected in the considerable number of studies that have reported $\mathrm{CO}_{2}$ fluxes and soil gas concentrations. This information has been of interest both to ecologists, microbiologists, and plant scientists evaluating plant growth, and to earth scientists interested in mineral weathering rates and groundwater composition.

To date, the predictive models have been mostly regression equations which fit $\mathrm{CO}_{2}$ concentrations to selected variables in specific ecosystems. As a result the models have differed in their conclusions as to which parameters are required. Some models have considered precipitation or soil water content to be the dominant factor while other models have considered the influence of temperature to be dominant. The importance of various factors clearly depends on which is the most limiting in any given instance. For example, Amundson and Smith [1988] reported that for an uncultivated soil, $\mathrm{CO}_{2}$ concentrations decreased with increasing temperature (at high soil temperatures the soils were dry), while for a cultivated soil (with adequate soil water) $\mathrm{CO}_{2}$ concentrations increased with increasing temperature.

An example of such a regression model is the model reported by Kiefer [1990], which was successful in simulating average root zone $\mathrm{CO}_{2}$ concentrations at Pigeon Mountain, Georgia, for a humid subtropical climate. The developed relationship, which requires input data of actual evapotranspiration, is as follows:

$$
\mathrm{CO}_{2}=\frac{4.17}{1+\exp \left(3.0707-0.271 \mathrm{ET}_{u}\right)}
$$

where $\mathrm{ET}_{a}$ is the mean actual evapotranspiration (millimeters) for 14 days prior to the predicted $\mathrm{CO}_{2}$ concentration

\footnotetext{
${ }^{1}$ On leave from Research Institute for Soil Reclamation and Protection, Prague, Czechoslovakia.

This paper is not subject to U.S. copyright. Published in 1993 by the American Geophysical Union.

Paper number 92WR02226.
}

(percent). The use of actual evapotranspiration essentially combines both temperature and water availability, which may well represent $\mathrm{CO}_{2}$ production, but other factors such as water inputs, soil hydraulic properties, and air-filled porosity also affect the $\mathrm{CO}_{2}$ concentration in the soil. Gunn and Trudgill [1982] reported that neither consideration of temperature nor soil water content could satisfactorily explain variations in soil $\mathrm{CO}_{2}$ concentrations in two study areas located in Andosol soils of New Zealand. They conclude ( $p, 93)$ that soil $\mathrm{CO}_{2}$ concentrations at any particular point in space and
time would appear to depend at least as much on local factors
controlling soil gas diffusivity as on the weather parameters
which control production rates.

Thus even if a model is successful for a specific location, if it is not process oriented, it may not be applicable to environments other than that for which it was developed. There are only a small number of models that are not based on a single experimental regression. These models mostly do not consider transient water flow or the influence of temperature and assume that molecular diffusion in the gas phase is the only transport mechanism [e.g., de Jong and Schappert, 1972; Solomon and Cerling, 1987]. Also these models do not attempt to describe the complex biological processes of $\mathrm{CO}_{2}$ production.

The model SOILCO2, described in paper 1 [Šimüinek and Suarez, this issue], is intended as a generalized model that considers the processes of $\mathrm{CO}_{2}$ production, water movement and $\mathrm{CO}_{2}$ and heat transport; thus the input data requirements are greater than those required for both the regression models and simpler process-based models. However, once the soil hydraulic properties are obtained, the model input requires only easily obtained climatological information such as temperature and water input and agronomic information such as crop type and planting date.

In this paper we present a sensitivity analysis of the model output to the input parameters for a relatively simplified system, with the objective of determining which parameters require site-specific information and which parameters can 
utilize existing area or ecosystem data bases. Additional sensitivity analysis is made for a real field system to evaluate the relative importance of different transport mechanisms and the consideration of partitioning $\mathrm{CO}_{2}$ between liquid and gas phases. Next, we select parameter values for optimal plant and microbial $\mathrm{CO}_{2}$ production and production dependence on temperature, water content, osmotic potential and gas composition for plant and microbial respiration, all based on literature review. We also evaluate the model in its full complexity using published soil $\mathrm{CO}_{2}$ data bases as well as data collected for model evaluation.

\section{Sensitivity Analysis}

In this section we present a sensitivity analysis of the model parameters which affect $\mathrm{CO}_{2}$ concentrations in the soil. A sensitivity analysis serves to enhance an understanding of a model response to changes in individual parameters. This information is useful both to evaluate the potential errors associated with parameter uncertainty and to determine which parameters need to be more accurately characterized. The sensitivity analysis is divided into two parts. In Section 2.1 we present the sensitivity analysis for a simplified system with time and depth invariant temperature and water content. In section 2.2 we evaluate the significance of specific parameters and assumptions about $\mathrm{CO}_{2}$ transport for a transient water flow system.

\subsection{Steady State Water Flow System}

For a simplified system we assume that the temperature and water content are time invariant. The water uptake and $\mathrm{CO}_{2}$ production by plant roots were also neglected in this analysis. The governing equation for $\mathrm{CO}_{2}$ transport for this simplified system has the form

$$
\left(\theta_{a}+K_{H} R T \theta_{w}\right) \frac{\partial c_{a}}{\partial t}=D_{E} \frac{\partial^{2} c_{a}}{\partial z^{2}}-q_{E} \frac{\partial c_{a}}{\partial z}+S
$$

where $\theta_{a}$ and $\theta_{w}$ are the volumetric air and water contents, respectively, $c_{a}$ is the $\mathrm{CO}_{2}$ concentration in the gas phase, $D_{E}$ is the effective dispersion coefficient for $\mathrm{CO}_{2}$ in the soil matrix, $q_{E}$ is the effective velocity of $\mathrm{CO}_{2}, S$ is the total $\mathrm{CO}_{2}$ production, $K_{H}$ is the Henry's law constant, $R$ is the universal gas constant, $T$ is the absolute temperature, $t$ is time and $z$ is the spatial coordinate. The terms $D_{E}$ and $q_{E}$ are defined in detail in paper 1 [Šimüek and Suarez, this issue]. For the sensitivity analysis we consider only the depth and $\mathrm{CO}_{2}$ concentration reduction of the total $\mathrm{CO}_{2}$ production, $S$ :

$$
S=\gamma_{0} f(z) f\left(c_{a}\right)
$$

where $\gamma_{0}$ represents the optimal $\mathrm{CO}_{2}$ production for the whole soil profile at $20^{\circ} \mathrm{C}$ and $f(z)$ and $f\left(c_{a}\right)$ are the reduction coefficients dependent on depth and $\mathrm{CO}_{2}$ concentration, respectively. The depth-dependent reduction coefficient, $f(z)$, is defined similar to the water uptake function of Raats [1974] as

$$
f(z)=a e^{-a z}
$$

where $a$ is an empirical constant. The production response to the $\mathrm{CO}_{2}$ concentration is based on the Michaclis-Menton equation as given by Šmunek and Suarez [this issue]:

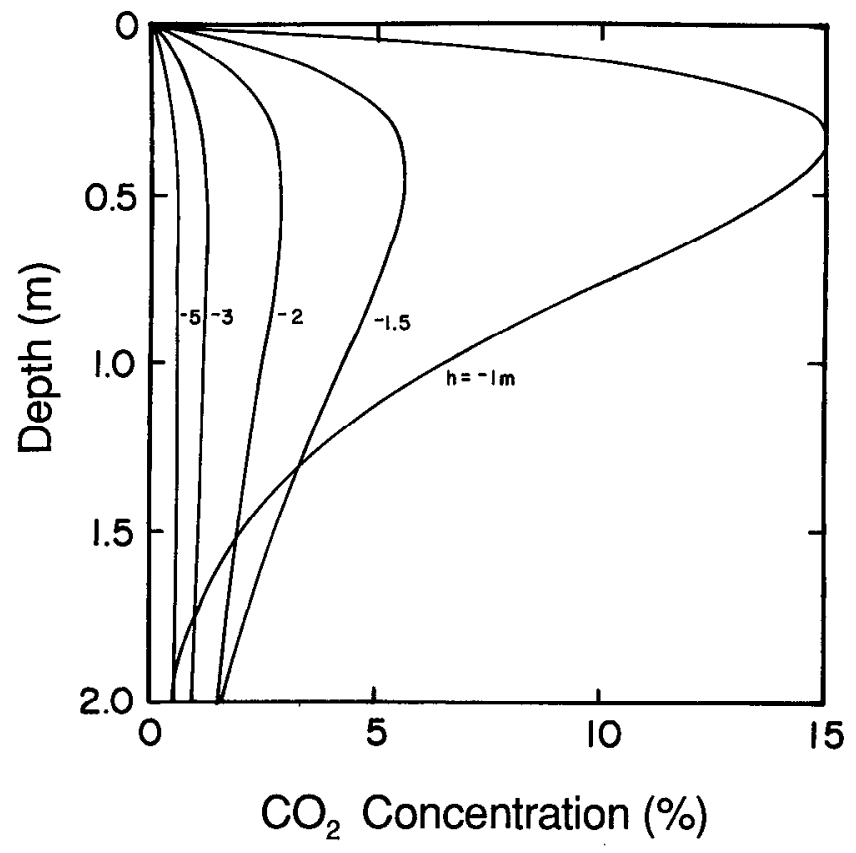

Fig. 1. Calculated $\mathrm{CO}_{2}$ concentration profiles for different values of the pressure head, $h$, after 100 days.

$$
f\left(c_{a}\right)=\frac{0.21-c_{a}}{0.42-c_{a}-K_{M}^{*}}
$$

where $K_{M}^{*}$ is the Michaelis constant for the $\mathrm{CO}_{2}$ concentration, i.e., the $\mathrm{CO}_{2}$ concentration for which the $\mathrm{CO}_{2}$ production is reduced by half. The water and air content are mutually dependent variables

$$
\theta_{a}+\theta_{w}=p
$$

where $p$ is porosity.

We performed a sensitivity analysis on the following parameters: water pressure head (which defines the air and water contents, $\theta_{a}$ and $\theta_{w}$, respectively, through the water retention curve), $h$; optimal $\mathrm{CO}_{2}$ production, $\gamma_{0}$; production distribution with depth as reflected by parameter $a$; and direction of water flow. We assume in these simulations that the water and air are stagnant, if not mentioned otherwise. Except for the analyzed variables, the other variables have the following values: $h=-1.50 \mathrm{~m}, a=5 \mathrm{~m}^{-1}, \gamma_{0}=0.002$ $\mathrm{m}^{3} \mathrm{~m}^{-2} \mathrm{~d}^{-1}$. The $\mathrm{CO}_{2}$ concentration reduction coefficient was considered to have the value of $K_{M}^{*}=0.19 \mathrm{~m}^{3} \mathrm{~m}^{-3}$. The transport parameters of $\mathrm{CO}_{2}$, such as diffusion coefficients in air and water, were taken from Glinski and Stepniewski [1985] and the temperature-dependent $\mathrm{CO}_{2}$ solubility constants from Harned and Davis [1943], for both the sensitivity analysis and the model evaluation presented in the following sections. A constant temperature of $20^{\circ} \mathrm{C}$ was considered. Instead of the steady state concentration profiles we present the profiles after 100 days. The initial conditions throughout the whole profile, as well as the upper boundary condition at the soil surface, were constant $\mathrm{CO}_{2}$ concentration at the atmospheric value of $0.035 \%$. A zero concentration gradient was considered as the lower boundary condition at a depth of $5 \mathrm{~m}$.

2.1.1. Pressure head-water content. Figure 1 shows the dependence of the concentration profiles on the water 
pressure heads, $h$, in the interval $-1.0 \mathrm{~m}$ through $-5.0 \mathrm{~m}$. The pressure heads $-1.0,-1.5,-2.0,-3.0$ and $-5.0 \mathrm{~m}$ correspond to the volumetric water contents of $0.339,0.304$, $0.276,0.233$ and 0.182 , and volumetric air contents of 0.068 , $0.103,0.131,0.174,0.225$, respectively, for Pachappa fine sandy loam [Richards, 1952]. For large negative pressure heads, i.e., a relatively dry soil profile, there was enough free space in the profile for gas diffusion to maintain low $\mathrm{CO}_{2}$ concentrations. High diffusion rates cause a fast redistribution of $\mathrm{CO}_{2}$ in the profile as well as a high evolution of $\mathrm{CO}_{2}$ to the atmosphere. As a result, in dry soils, the concentration gradient in the soil is small and the $\mathrm{CO}_{2}$ concentrations are low.

At low negative pressure heads, i.e., a wet soil profile, gas diffusion is hindered by the lack of free space and the increased tortuosity. Reduced diffusion rates caused by small diffusion coefficients limit the redistribution of $\mathrm{CO}_{2}$ in the profile as well as the evolution of $\mathrm{CO}_{2}$ to the atmosphere. Thus, at low negative pressure heads the concentration gradient in the soil is large and the $\mathrm{CO}_{2}$ concentrations are high. Figure 1 reflects the fact that the $\mathrm{CO}_{2}$ concentrations at greater depths are low for both high and low water contents; in the former case this is caused by low diffusion and limited redistribution, and in the latter case this is due to the very fast evolution of $\mathrm{CO}_{2}$ to the atmosphere. If the same conditions of high water content prevail for a larger time period, the $\mathrm{CO}_{2}$ concentration would rise to high values throughout the whole profile. At high water contents, the $\mathrm{CO}_{2}$ concentration in the upper part of the profile rises to such high values that the $\mathrm{O}_{2}$ concentration is deficient and the $\mathrm{CO}_{2}$ production almost ceases in this part of the soil profile. In our simulations we assumed that the respiratory quotient, which is the ratio of $\mathrm{CO}_{2}$ produced to $\mathrm{O}_{2}$ consumed, is equal to unity. Clearly this is not reasonable where anaerobic conditions may prevail and respiratory quotients can approach values of 2-3 [Rixon and Bridge, 1968]; this may not adversely affect our simulations since, in any case, the absolute respiratory rates are very low under oxygen deficient conditions.

Since the range in pressure head given in Figure 1 is experienced regularly in all types of soils, it is essential that the model accurately represent pressure head changes with time. These values depend in part on the hydraulic properties of the soil. In view of the difficulties in accurately predicting the soil water content under field conditions, this variable is likely the most limiting factor to accurately predict $\mathrm{CO}_{2}$ concentrations in the soil.

2.1.2. Production. The $\mathrm{CO}_{2}$ profile concentrations are dependent on the rate of production, $\gamma_{0}$, as is demonstrated by the results in Figure 2. In this example we chose a relatively wet soil (pressure head $h$ of $-1.5 \mathrm{~m}$ ) and production values from 0.001 to $0.005 \mathrm{~m}^{3} \mathrm{~m}^{-2} \mathrm{~d}^{-1}$, which represent the yearly variations in a cropped soil in England as reported by Currie [1975] (cited by Glinski and Stepniewski [1985]). The specific water content influences the range of $\mathrm{CO}_{2}$ values; nevertheless, for relatively wet conditions a typical range in the production term will result in a large range in $\mathrm{CO}_{2}$ concentrations. From the simulations shown in Figure 2 , it is clear that soil productivity is one of the critical factors in predicting $\mathrm{CO}_{2}$ concentrations and that a successful model must properly represent this variable. Nonetheless, the influence of variations in optimal production is far less than indicated either by an initial examination of Figure 2 or by

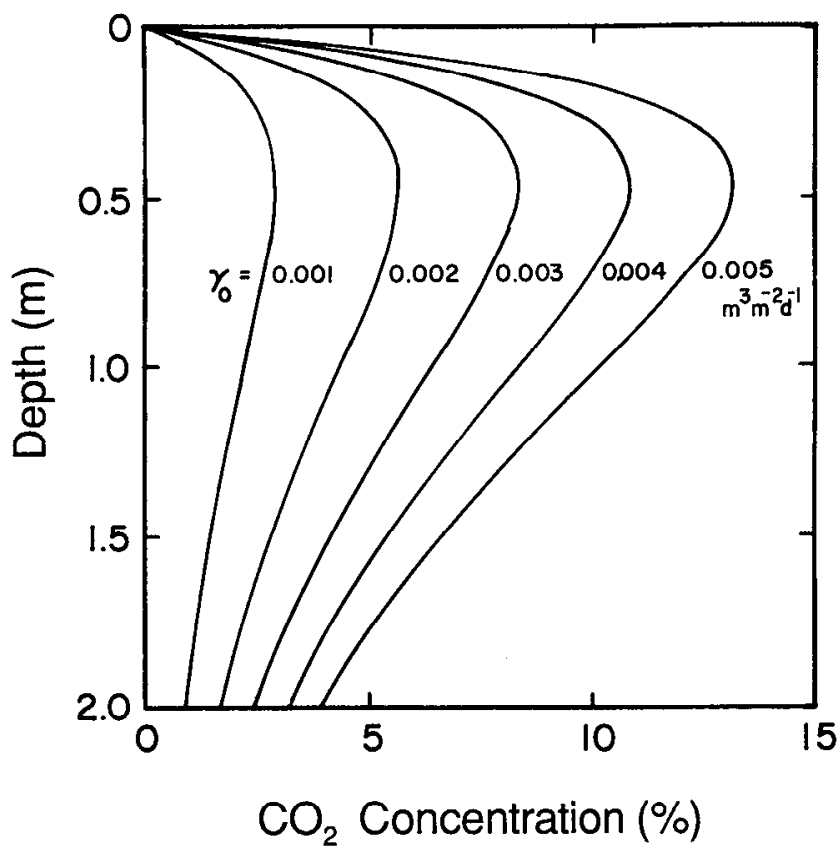

Fig. 2. Calculated $\mathrm{CO}_{2}$ concentration profiles for different values of the rate of production, $\gamma_{0}$, after 100 days.

comparing reported respiration rates. Data reported in the literature exhibit a very wide range in respiration rates, mostly because conditions which inhibit respiration are not considered. For example, tropical soils have been reported with production, $S$, as high as $0.03 \mathrm{~m}^{3} \mathrm{~m}^{-2} \mathrm{~d}^{-1}$ and, under extremely dry or cold conditions, production can approach zero [Glinski and Stepniewski, 1985]. These values represent actual measurements under various conditions of stress and temperature. Rather than attempt to select specific production values we selected an optimum $\mathrm{CO}_{2}$ production value and calculate actual production rates. The model considers optimal production of $\mathrm{CO}_{2}$ for the whole soil profile which is then exponentially distributed throughout the profile and modified by additional reduction coefficients for oxygen, water and osmotic stress, temperature and time. Calculation of actual $\mathrm{CO}_{2}$ production by the model requires that the reduction coefficient function properly represents the ecosystem response to that variable.

2.1.3. Production distribution with depth. Figure 3 shows the dependence of $\mathrm{CO}_{2}$ concentrations on the depth distribution of production in the soil profile as reflected by changes in the $a$ parameter in (4). This parameter describes the exponential distribution of $\mathrm{CO}_{2}$ production within the soil profile. Larger values of $a$ shift the production closer to the soil surface while for smaller values of $a$ the production is distributed more evenly throughout the profile. Large values of $a$ result in a very fast evolution of $\mathrm{CO}_{2}$ into the atmosphere so that high levels of $\mathrm{CO}_{2}$ concentration cannot occur. With progressively smaller values of $a$, the flux becomes smaller and the maximum in the $\mathrm{CO}_{2}$ concentration is located deeper in the soil profile, with the highest maximum value of $\mathrm{CO}_{2}$ concentration at an intermediate value of $a \approx 1 \mathrm{~m}^{1}$ (Figure 3). Rooting distribution is an important parameter affected by plant type, soil physical conditions with depth, and irrigation frequency, among other variables. In contrast to uncertainties about the dimensionless rooting 


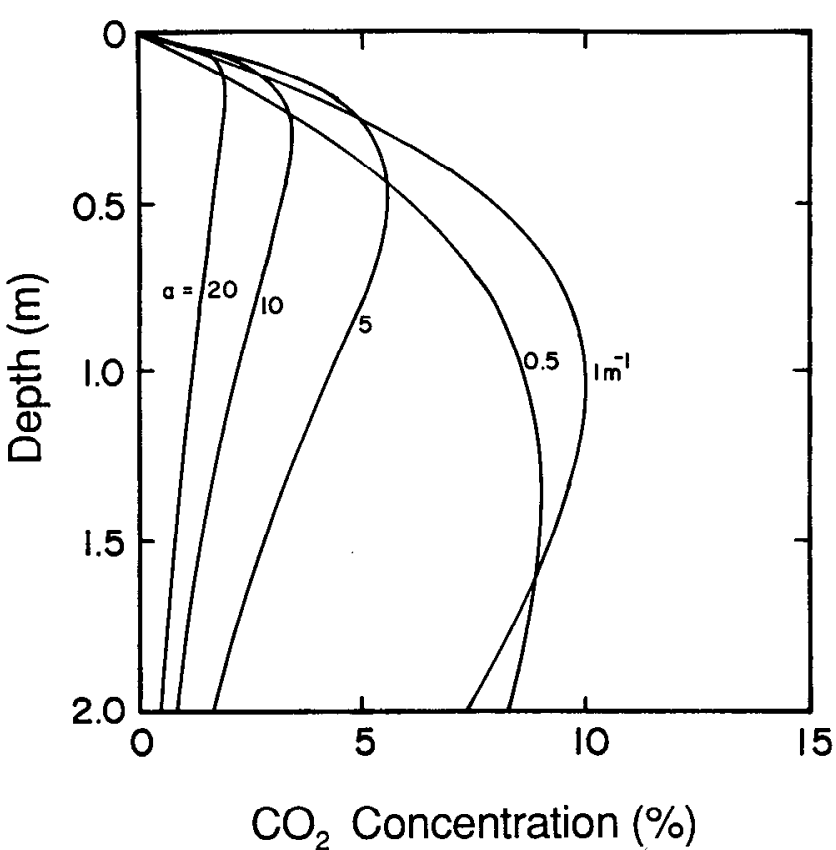

Fig. 3. Calculated $\mathrm{CO}_{2}$ concentration profiles for different depth distributions of the $\mathrm{CO}_{2}$ production, as reflected by the parameter $a$, after 100 days.

distribution function, the maximum rooting depth can be estimated reasonably well for any specific site.

2.1.4. Waterflow. The dependence of $\mathrm{CO}_{2}$ soil concentration on the direction of water flow is presented in Figure 4. Three cases were studied: no flow and downward and upward water flow $\left(q_{E}=0,0.828,-0.828 \mathrm{~cm} \mathrm{~d}^{-1}\right.$, respectively). In this analysis we maintained a fixed, uniform water distribution and varied only the water flow. The

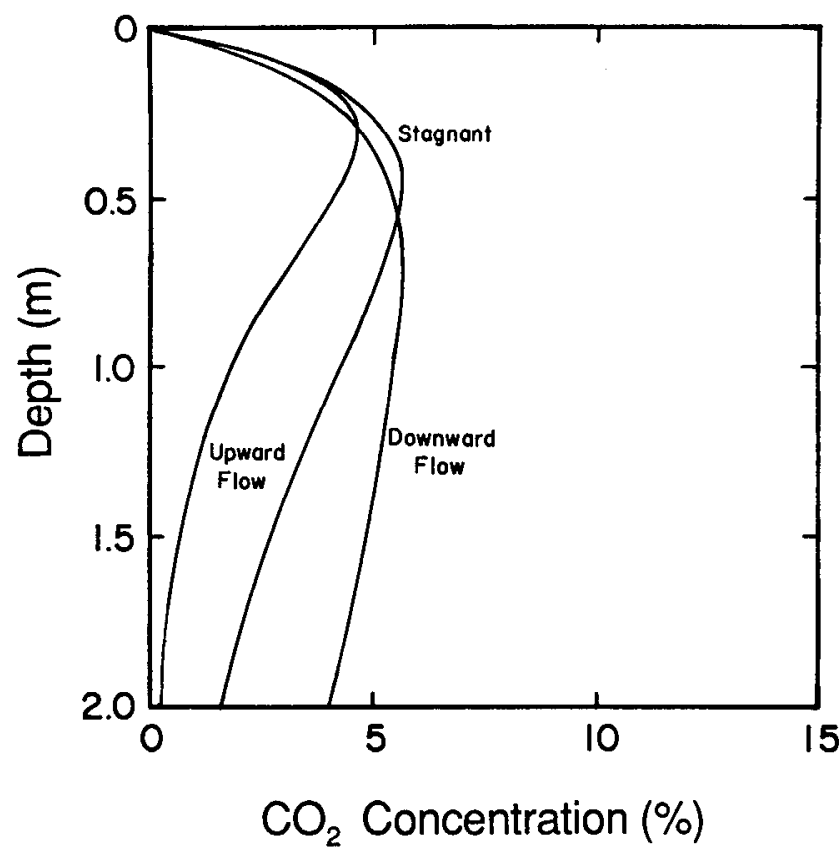

Fig. 4. Calculated $\mathrm{CO}_{2}$ concentration profiles for different directions of water flow after 100 days. direction of flow influences the $\mathrm{CO}_{2}$ profiles significantly by redistributing $\mathrm{CO}_{2}$ in the direction of water flow because of $\mathrm{CO}_{2}$ transport in the water phase. During upward water flow, $\mathrm{CO}_{2}$ is transported faster to the soil surface than when no flow occurs; dissolution into the water phase causes a lower $\mathrm{CO}_{2}$ concentration in the lower part of the profile, a higher $\mathrm{CO}_{2}$ gradient near the soil surface and a higher rate of evolution. During downward water flow, dissolved $\mathrm{CO}_{2}$ is transported into the deeper horizons, decreasing the $\mathrm{CO}_{2}$ concentrations in the main production zone and increasing the $\mathrm{CO}_{2}$ concentrations in the deeper horizons. Overall, $\mathrm{CO}_{2}$ evolution into the atmosphere is much lower for downward flow than for the no flow and upward flow cases. Decreasing the $\mathrm{CO}_{2}$ concentrations in the main production zone also results in greater production of $\mathrm{CO}_{2}$ because the model reduces production at low $\mathrm{O}_{2}$ concentrations. Under field conditions the water flow should therefore be calculated sufficiently accurately to generate minimal uncertainty in the model output.

\subsection{Trunsient Water Flow System}

In this section we evaluate the significance of particular parameters, such as root distribution, optimal $\mathrm{CO}_{2}$ production, hydraulic characteristics and the use of different simplified assumptions, concerning $\mathrm{CO}_{2}$ transport with transient water flow. The model was run with all boundary conditions for water flow and $\mathrm{CO}_{2}$ and heat transport and all coefficients for $\mathrm{CO}_{2}$ production and root water uptake taken from the wheat field experiment described by Buyanovsky and Wagner [1983] [also partially described below). The only differences between simulations in this section and simulations described later are the different hydraulic characteristics and thermal properties of the soil (Table 1) and the investigated variables.

2.2.1. Hydraulic characteristics. To cvaluate the influence of soil texture on $\mathrm{CO}_{2}$ concentrations in the soil profile, we utilized the parameters presented by Hillel and van Bavel [1976] for three idealized soils representing sand, loam and clay. Although there are differences in total porosity, the major differences being examined are the hydraulic characteristics of soils of different texture. The water retention and soil hydraulic conductivity functions of the selected soils are presented in Figure 5. These curves were generated with parameters obtained from the nonlinear least squares fitting program of van Genuchten [1978]. The parameters in the thermal conductivity equation [Šminek and Suarez, this issue, equation (53)] were taken from Chung and Horton [1987].

The $\mathrm{CO}_{2}$ concentration profiles predicted for the $20 \mathrm{~cm}$

TABLE 1. Parameters of the Soil Hydraulic and Thermal Characteristics

\begin{tabular}{lcccc}
\hline \multicolumn{1}{c}{ Parameter } & Sand & Loam & Clay & Pachappa \\
\hline$K_{s}, \mathrm{~m} \mathrm{~d}^{-1}$ & 2.16 & 0.605 & 0.173 & 0.25 \\
$\theta_{s}$ & 0.440 & 0.480 & 0.520 & 0.407 \\
$\theta_{r}$ & 0.000 & 0.000 & 0.000 & 0.000 \\
$\alpha, \mathrm{m}^{-1}$ & 2.57 & 1.50 & 0.86 & 0.76 \\
$n$ & 2.138 & 1.592 & 1.301 & 1.569 \\
$b_{1}, \mathrm{~W} \mathrm{~m}^{-1} \mathrm{~K}^{-1}$ & 0.228 & 0.243 & -0.197 & 0.243 \\
$b_{2}, \mathrm{~W} \mathrm{~m}^{-1} \mathrm{~K}^{-1}$ & -2.406 & 0.393 & -0.962 & 0.393 \\
$b_{3}, \mathrm{~W} \mathrm{~m}^{-1} \mathrm{~K}^{-1}$ & 4.909 & 1.534 & 2.521 & 1.534 \\
\hline
\end{tabular}



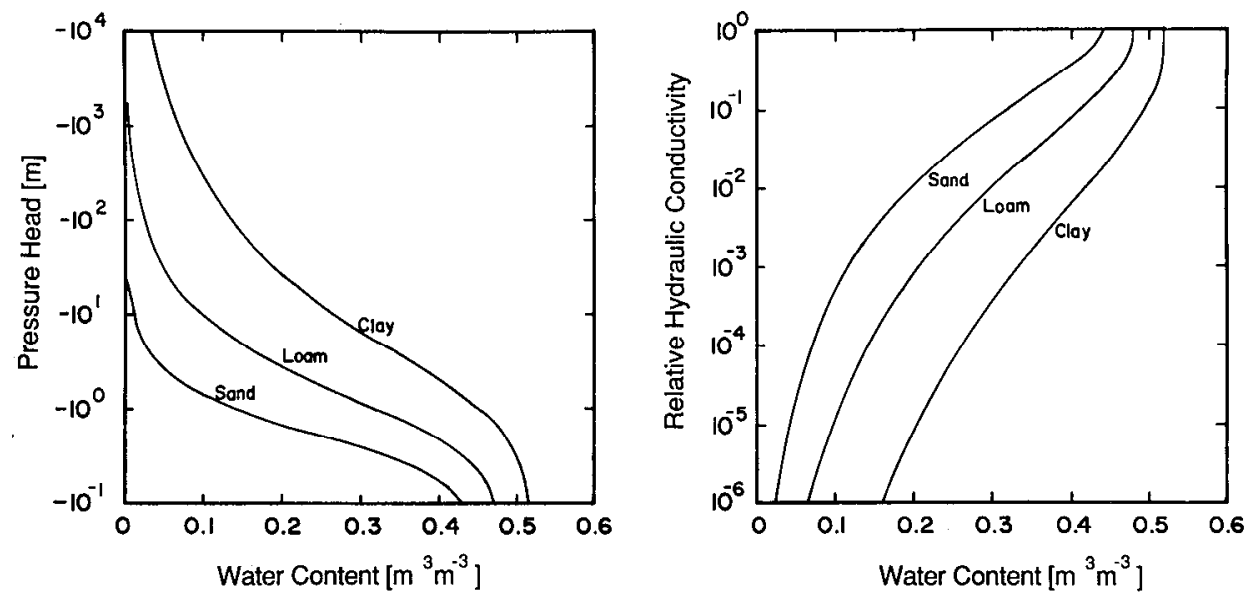

Fig. 5. Water retention and relative hydraulic conductivity functions for the sand, loam, and clay calculated from data of Hillel and van Bavel [1976].

depth are given for the three idealized soils in Figure 6. The profiles in this figure show that differences in hydraulic characteristics cause large differences in $\mathrm{CO}_{2}$ concentrations with the same water management. The most significant cause of these differences is the air content available for diffusion of $\mathrm{CO}_{2}$. The $\mathrm{CO}_{2}$ diffusion in air is about 10,000 times larger than diffusion in water; thus the water phase, except at high flow velocities, acts mostly as a storage phase for $\mathrm{CO}_{2}$ rather than as a transport medium. The water content for the sand was mostly in the range from 0.07 to 0.20 , resulting in an air content of about $0.24-0.37$. In contrast, for the loam, the water and air content ranges were from 0.15 to 0.33 and from 0.15 to 0.33 , respectively, and for the clay, from 0.40 to 0.49 and from 0.03 to 0.12 , respectively.

The high water contents in the clay simulation decreased diffusion and evolution of $\mathrm{CO}_{2}$ to the atmosphere. Since the tortuosity for the clay is much greater at high water content and, therefore, the effective diffusion coefficient is smaller, the concentration gradient near the soil surface is much larger in order for evolution to keep up with $\mathrm{CO}_{2}$ production in the profile. Consequently, the $\mathrm{CO}_{2}$ concentrations are

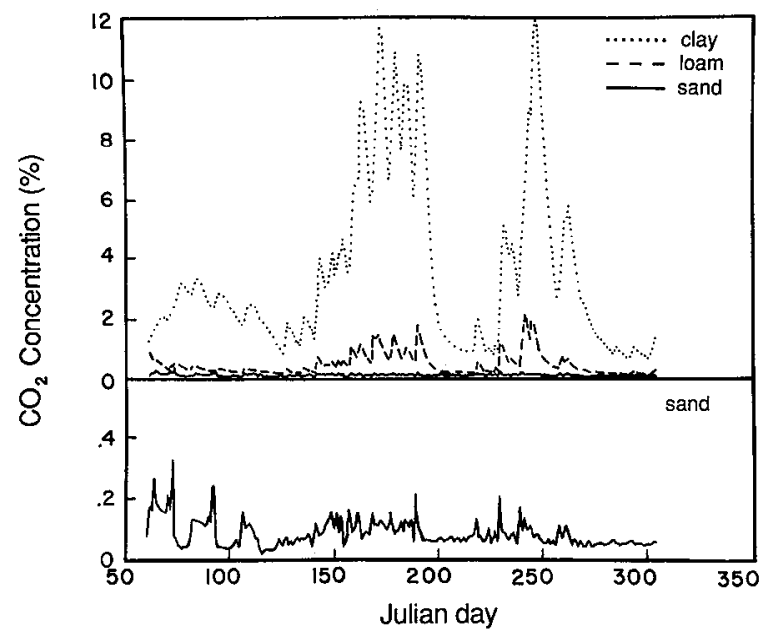

Fig. 6. Simulated $\mathrm{CO}_{2}$ concentration with time at $20 \mathrm{~cm}$ depth for threc idcalized soils: clay, loam and sand, using the boundary conditions given by Buyanovsky and Wagner [1983] for wheat. significantly higher throughout the soil profile for the clay as compared to the loam and sand. The $\mathrm{CO}_{2}$ concentrations are lower in the deeper horizons because there was insufficient time for $\mathrm{CO}_{2}$ to diffuse to that depth (data not shown). In addition to the absolute concentrations the variations in $\mathrm{CO}_{2}$ concentrations with time are very dependent on soil texture. It can be seen in Figure 6 that the clay soil undergoes tenfold variations in $\mathrm{CO}_{2}$ while for sandy soil the variations are only a factor of 2-3. These differences are related to the fact that the sandy soil maintained high values for air porosity which was not the case for the clay soil. As a result the $\mathrm{CO}_{2}$ concentration of sandy soils is much less sensitive to infiltration events than that for clay soils.

2.2.2. Production. The evaluation of the sensitivity of $\mathrm{CO}_{2}$ concentration to changes in production utilized the production range of $0.005-0.009 \mathrm{~m}^{3} \mathrm{~m}^{-2}$, which we consider to be a likely range for optimum production $\left(20^{\circ} \mathrm{C}\right.$ and no stress) of commercial crops. As shown in Figure 7 the $\mathrm{CO}_{2}$ concentrations increased with increased $\mathrm{CO}_{2}$ production but the concentration is not extremely sensitive to the optimum production term. In periods of relatively low water content the $\mathrm{CO}_{2}$ concentration is almost unaffected by a doubling of the production, while at high water content the $\mathrm{CO}_{2}$ concen-

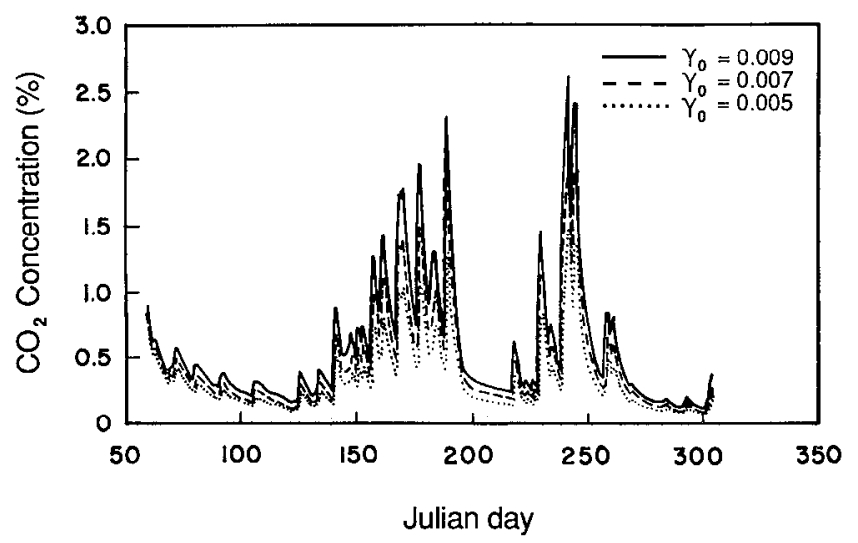

Fig. 7. Simulated $\mathrm{CO}_{2}$ concentration with time at $20 \mathrm{~cm}$ depth with different optimum production values using the boundary conditions given by Buyanovsky and Wagner [1983] for wheat. 


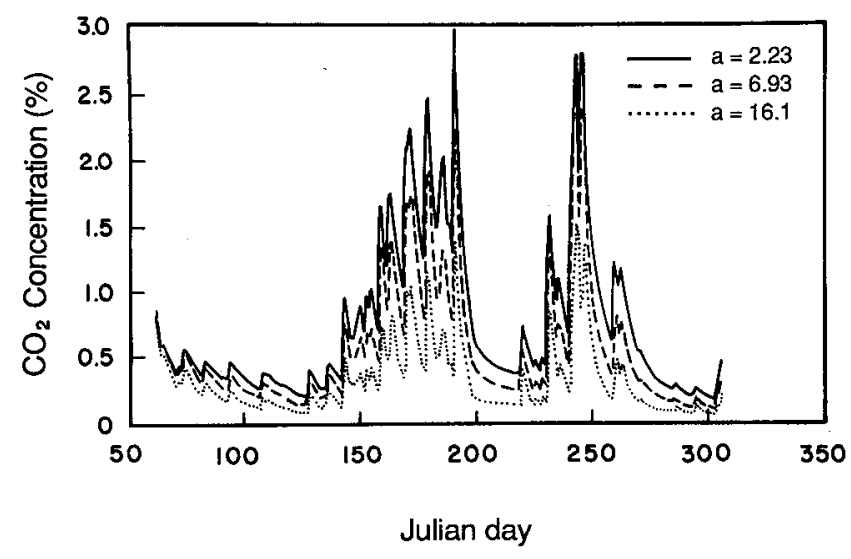

Fig. 8. Simulated $\mathrm{CO}_{2}$ concentration with time at $20 \mathrm{~cm}$ depth with different root distributions using the boundary conditions given by Buyanovsky and Wagner [1983] for wheat.

tration is approximately proportional to the increase in production.

2.2.3. Production distribution with depth. The changes in $\mathrm{CO}_{2}$ concentration with time at the $20 \mathrm{~cm}$ depth are presented in Figure 8 with different $a$ parameters $(2.23,6.93$, 16.1) corresponding to 20,50 , and $80 \%$ of the roots being in the upper $10 \mathrm{~cm}$. The shallower the root distribution, the lower the $\mathrm{CO}_{2}$ concentration for all but the near-surface horizon. The sensitivity to the root parameter values is much greater at depth than in the near-surface environment, as is evident from the concentration profiles in Figure 9 for four dates from the simulation shown in Figure 8. Generalized soil or crop rooting distributions appear adequate for predicting root zone concentration profiles, but more detailed site-specific information may be needed to predict groundwater recharge values.

2.2.4. Transport assumptions. One of the major differences between this model and earlier models concerns the assumptions regarding $\mathrm{CO}_{2}$ movement. In this analysis we calculated $\mathrm{CO}_{2}$ distributions with three different assumptions about the $\mathrm{CO}_{2}$ transport for two different soils, clay and loam. In the first case partitioning between the gas and liquid phases is not considered and the gas phase is consid-

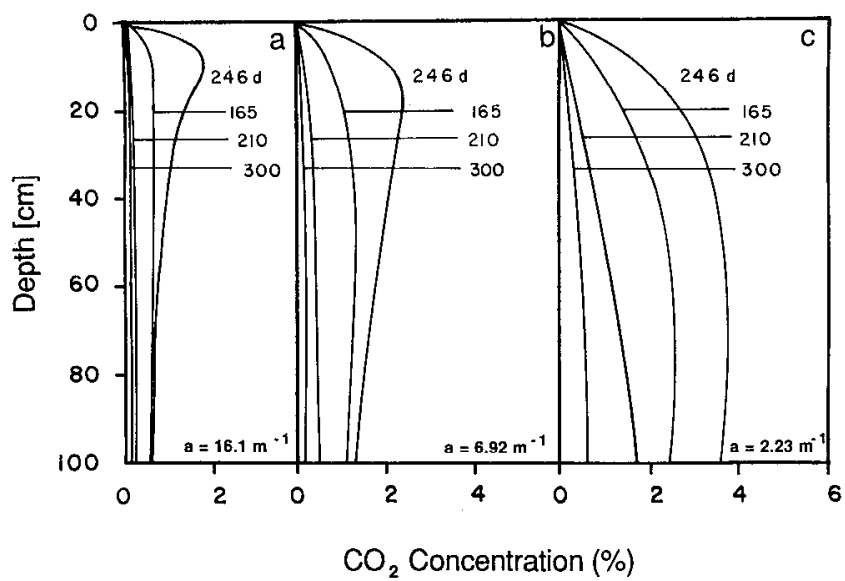

Fig. 9. Simulated $\mathrm{CO}_{2}$ concentration profiles for day 165, 210, 246 , and 300 with different root distributions using the boundary conditions given by Buyanovsky and Wagner [1983] for wheat.
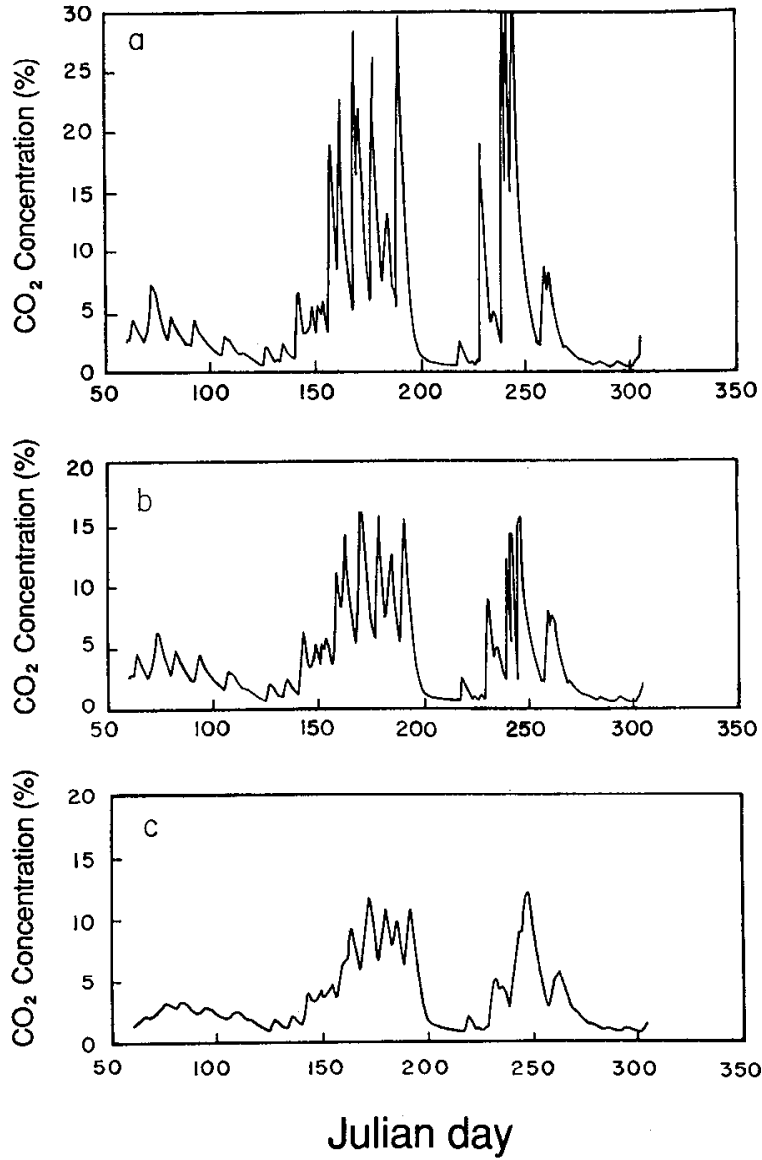

Fig. 10. Simulated $\mathrm{CO}_{2}$ concentration with time for a clay soil at $20 \mathrm{~cm}$ depth with three different assumptions regarding gas flow using the boundary conditions given by Buyanovsky and Wagner [1983] for wheat.

ered constant [de Jong and.Schappert, 1972; Solomon and Cerling, 1987]. As shown in Figure 10a, fast changes in water content cause very sudden increases or decreases in $\mathrm{CO}_{2}$ concentration as well as the unrealistic result of concentrations in excess of $30 \%$. In reality, these sudden changes and very large $\mathrm{CO}_{2}$ concentrations do not occur. The $\mathrm{CO}_{2}$ gas-liquid partitioning coefficient is close to one; thus upon an increase in water content, $\mathrm{CO}_{2}$ is dissolved in the water phase without significant changes in concentration. In the second case we still do not consider partitioning between the two phases but the gas phase is considered mobile, as described in the companion paper [Šimunek and Suarez, this issue]. By mobile gas phase we mean that the gas flows in the opposite direction to the water and that water volume changes are matched by gas volume changes (of opposite sign). As shown in Figure $10 b$ the fluctuations in $\mathrm{CO}_{2}$ are much smaller when gas displacement is considered. In the third case, both mobile water and gas-liquid partitioning are considered, as utilized in our SOILCO2 model. The simulation shown in Figure $10 c$ demonstrates the importance of these processes, as the concentration increases after water infiltration events are much lower than predicted using the more simplified assumptions.

The simulations shown in Figure 11 used the same parameters as those used for Figure 10 except that the hydraulic properties were those for a loam soil rather than a clay soil. 

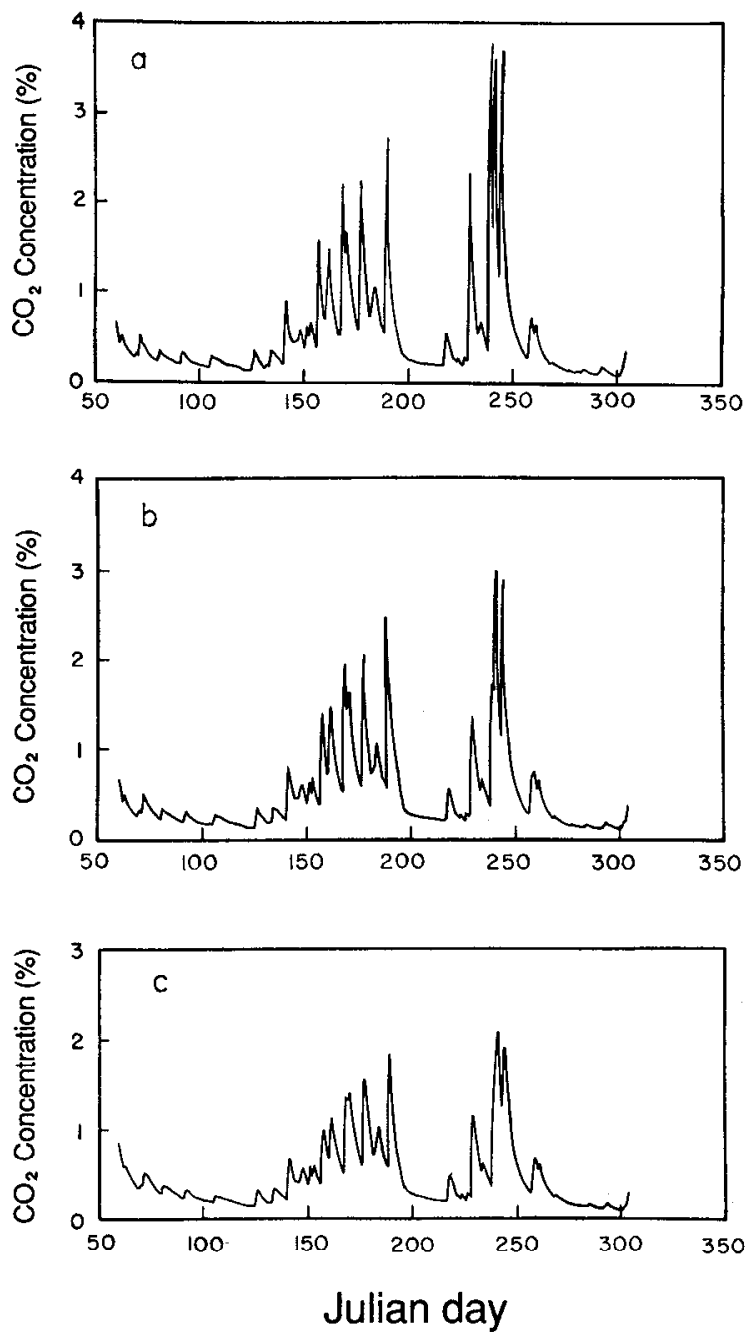

Fig. 11. Simulated $\mathrm{CO}_{2}$ concentration with time for a loam soil at $20 \mathrm{~cm}$ depth with three different assumptions regarding gas flow using the boundary conditions given by Buyanovsky and Wagner [1983] for wheat.

A comparison of the simulations in Figure 10 and Figure 11 shows that the errors associated with the simplified assumptions of the first and second cases given above, are much smaller for coarser soils as compared to finer textured soils. In addition, the $\mathrm{CO}_{2}$ concentrations in the loam soil (Figure $11 c$ ) are about $20 \%$ of the values for the clay soil (Figure $10 \mathrm{c}$ ). These results illustrate the importance of soil texture and hydraulic properties for $\mathrm{CO}_{2}$ concentrations and the necessity of using the more complete model assumptions of the third case, especially for fine textured soils.

\section{Parameter Selection}

In this section we discuss selection of parameter values for $\mathrm{CO}_{2}$ production based on a review of the literature. The total $\mathrm{CO}_{2}$ production was defined in paper 1 [Šimünek and Suarez, this issue] as the sum of plant root and microbial respiration:

$$
S=\gamma_{s}+\gamma_{p}=\gamma_{s 0} \prod_{i} f_{s i}+\gamma_{p 0} \prod_{i} f_{p i}
$$

where $S$ is the total $\mathrm{CO}_{2}$ production, $\gamma_{s}$ and $\gamma_{p}$ are the $\mathrm{CO}_{2}$ production by the soil microorganisms or plant roots, respectively, and $f_{s i}$ and $f_{p i}$ are the reduction coefficients reflecting the influence of temperature, $\mathrm{CO}_{2}$ concentration, depth, pressure and osmotic stress, and time. The terms $\gamma_{s 0}$ and $\gamma_{p 0}$ represent the optimal $\mathrm{CO}_{2}$ production by the soil microorganisms or plant roots for the whole soil profile at $20^{\circ} \mathrm{C}$ under optimal water, solute and $\mathrm{CO}_{2}$ concentration conditions, respectively.

\subsection{Optimum Production at $20^{\circ} \mathrm{C}$}

For summer months, Lundegard [1927] calculated an average soil respiration of $0.005 \mathrm{~m}^{3} \mathrm{~m}^{-2} \mathrm{~d}^{-1}$ for oats and 0.0034 for cabbage. Monteith et al. [1964] reported $\mathrm{CO}_{2}$ fluxes in England of around $0.003 \mathrm{~m}^{3} \mathrm{~m}^{-2} \mathrm{~d}^{-1}$ for bare soil, and approximately $0.005 \mathrm{~m}^{3} \mathrm{~m}^{-2} \mathrm{~d}^{-1}$ for soils with different crops and with a soil temperature in the $10^{\circ}-15^{\circ} \mathrm{C}$ range. Buyanovsky et al. [1986] reported the $\mathrm{CO}_{2}$ flux from the surface of soil cultivated to wheat to be from about 0.0025 $\mathrm{m}^{3} \mathrm{~m}^{-2} \mathrm{~d}^{-1}$ in April to maximum values in July of 0.0095 , 0.007 , and $0.006 \mathrm{~m}^{3} \mathrm{~m}^{-2} \mathrm{~d}^{-1}$ for three years with wheat, with the maximum flux occurring at soil temperatures in excess of $20^{\circ} \mathrm{C}$. Data presented by de Jong and Schappert [1972] suggest that the average respiration in the summer is about $0.013 \mathrm{~m}^{3} \mathrm{~m}^{-2} \mathrm{~d}^{-1}$; however, temperature data were not reported. Values greater than $0.01 \mathrm{~m}^{3} \mathrm{~m}^{-2} \mathrm{~d}^{-1}$ are also possible under conditions where microbial decomposition and root respiration occur in a high-porosity litter layer on the surface, such as in tropical soils without biomass harvesting. We assume that the optimal production for the whole soil profile at $20^{\circ} \mathrm{C}, \gamma_{0}=\gamma_{s 0}+\gamma_{p 0}$, is in the range from 0.006 to $0.009 \mathrm{~m}^{3} \mathrm{~m}^{-2} \mathrm{~d}^{-1}$; thus, the variation in $\mathrm{CO}_{2}$ concentration as a result of this parameter is much less than a factor of 2 for any depth, as shown in Figure 2. Optimal production for any given ecosystem may be even less variable if we consider other factors such as soil nutrient status and plant type. We assume that root respiration is responsible for $40 \%$ of the total soil respiration. This value is consistent with Holt et al. [1990], who measured a value of 39\%, and Kucera and Kirkham [1971], who estimated a value of $37 \%$ from their data. In our simulations we chose an intermediate value of $0.007 \mathrm{~m}^{3} \mathrm{~m}^{-2} \mathrm{~d}^{-1}$ for the optimal production, where $\gamma_{s 0}=0.0042 \mathrm{~m}^{3} \mathrm{~m}^{-2} \mathrm{~d}^{-1}$ and $\gamma_{p 0}=$ $0.0028 \mathrm{~m}^{3} \mathrm{~m}^{-2} \mathrm{~d}^{-1}$.

\subsection{Production Response to Temperature}

The production coefficient response to temperature is based on the Arrhenius equation as given by Simünek and Suarez [this issue]:

$$
f(T)=\exp \left[\frac{E\left(T-T_{20}\right)}{R T T_{20}}\right]
$$

where $R$ is the universal gas constant $\left(8.314 \mathrm{~kg} \mathrm{~m}^{2} \mathrm{~s}^{-2} \mathrm{~K}^{-1}\right.$ $\mathrm{mol}^{-1}$ ), $T$ is absolute temperature, $E$ is the activation encrgy of the reaction and $T_{20}=293.15 \mathrm{~K}\left(20^{\circ} \mathrm{C}\right)$.

Carey and Berry [1978] reported a constant activation energy of $49.4 \mathrm{~kJ} \mathrm{~mol}^{-1}$ for the respiration of corn roots between $10^{\circ}$ and $35^{\circ} \mathrm{C}\left(116 \mathrm{~kJ} \mathrm{~mol}^{-1}\right.$ between $5^{\circ}$ and $\left.10^{\circ} \mathrm{C}\right)$ and $53.6 \mathrm{~kJ} \mathrm{~mol}^{-1}$ for barley roots for temperatures between $5^{\circ}$ and $35^{\circ} \mathrm{C}$. From these data we consider that the activation 
energy for root respiration can be well characterized by the value of $50 \mathrm{~kJ} \mathrm{~mol}^{-1}$.

A fairly wide range in activation values has been reported for soil microbial respiration. The coefficient $Q_{10}$ has often been used to represent the relative increase in respiration intensity per $10^{\circ} \mathrm{C}$ increase in temperature. A majority of the respiration studies report $Q_{10}$ values between 1.5 and 3.0, although Anderson [1973], for example, reported $Q_{10}$ values greater than 3 for a forest soil. We consider that measured values are often affected by limiting factors other than temperature. Witkamp [1969] calculated a value of 2.5 in the temperature range of $10^{\circ}-20^{\circ} \mathrm{C}$ for leaf litter bags; in the leaf litter layer the $Q_{10}$ value was slightly greater than 3.0, whereas for the whole soil the value was 1.5 . In a study of tree and shrub leaf litter decomposition, Howard and Howard [1979] calculated mean $Q_{10}$ values ranging from 2.29 to 2.56 for various species. From the data of Ross and Cairns [1978] we calculated a mean $Q_{10}$ value of 2.31 , based on laboratory measurements from nine grassland soils. They report that the $Q_{10}$ value decreased with increasing temperature, which is consistent with the use of the Arrhenius concept.

One of the few data sets where the water content was reported is that of Kucera and Kirkham [1971] who reported $\mathrm{CO}_{2}$ flux data as a function of temperature for different water contents. Eliminating data where saturation or water deficiency existed at the soil surface, we calculate a $Q_{10}$ value of 2.5. For a mesophytic forest stand dominated by poplar, Edwards and Sollins [1973] reported soil water content, temperature and $\mathrm{CO}_{2}$ evolution. In the temperature range of $10^{\circ}-20^{\circ} \mathrm{C}$, we calculated a $Q_{10}$ value of 1.8 for data at a relatively constant water content. Based on all measurements where water content was reported to be roughly constant we selected a $Q_{10}$ value of 2.1 , which corresponds to an activation energy of $55.5 \mathrm{~kJ} \mathrm{~mol}^{-1}$ for the temperature interval of $20^{\circ}-30^{\circ} \mathrm{C}$.

\subsection{Production Response to Oxygen Concentration}

The production response to the $\mathrm{CO}_{2}$ concentration is based on the Michaelis-Menton equation (5). Soil respiration rates decrease to half of their maximum value when the $\mathrm{O}_{2}$ concentration decreases below $0.02 \mathrm{~m}^{3} \mathrm{~m}^{-3}$ in the soil air [Glinski and Stepniewski, 1985]. Since we assume that the sum of the $\mathrm{CO}_{2}$ and $\mathrm{O}_{2}$ concentrations is constant and equal to $21 \%$ of the soil atmosphere, we use a $\mathrm{CO}_{2}$ Michaelis constant for soil respiration, $K_{M}^{*}$, equal to $0.19 \mathrm{~m}^{3} \mathrm{~m}^{-3}$. The critical oxygen concentration, below which respiration is reduced, is much higher for plant roots than for microorganisms. Luxmoore et al. [1970] reported the $\mathrm{O}_{2}$ Michaelis constant for excised maize roots to be within $0.07-0.12 \mathrm{~m}^{3}$ $\mathrm{m}^{-3}$, but Armstrong and Gaynard [1976] considered that for intact roots this constant can be much lower. In view of this consideration we selected a value at the lower end of the interval reported by Luxmoore et al. [1970], giving a calculated $\mathrm{CO}_{2}$ Michaelis constant for plant respiration of $K_{M}^{*}=$ $0.14 \mathrm{~m}^{3} \mathrm{~m}^{3}$.

\subsection{Production Response to Water and Osmotic Stress}

The plant $\mathrm{CO}_{2}$ production response function to water stress is represented by [Šmunek and Suarez; this issue]:

$$
f_{p}(h)=\frac{1}{1+\left(h / h_{50}\right)^{b}}
$$

where $h_{50}$ represents the pressure head at which the $\mathrm{CO}_{2}$ production rate is reduced by $50 \%$ and $b$ is an empirical constant. The osmotic stress response function, $f_{p}\left(h_{\phi}\right)$, is represented by an analogous expression, where both $h$ parameters are replaced by corresponding osmotic heads, $h_{\phi}$. We assigned a value of 3 to the $b$ parameter, which has been shown to represent osmotic stress for various crops [van Genuchten, 1987l. The $h_{\phi 50}$ value for osmotic stress is calculated for specific crops using the yield data reported by Maas [1990]. In the absence of specific solution composition data, we use the approximate relation between osmotic pressure, $\phi$ (kilopascals) and electrical conductivity, EC (decisiemens per meter) at $25^{\circ} \mathrm{C}$ [from Jurinak and Suarez, 1990],

$$
\phi=40 \mathrm{EC}
$$

The osmotic potential (kilopascals) can then be readily converted to osmotic head, $h_{\phi}[L]$.

We assume that the depth, osmotic head and water content reduction of $\mathrm{CO}_{2}$ production by plant roots is the same as the corresponding reduction of potential transpiration.

The soil $\mathrm{CO}_{2}$ production response function to water stress is represented by [Šimunek and Suarez; this issue]

$$
\begin{array}{ll}
f_{s}(h)=\frac{\log |h|-\log \left|h_{1}\right|}{\log \left|h_{2}\right|-\log \left|h_{1}\right|} & h \in\left(h_{2}, h_{1}\right) \\
f_{s}(h)=\frac{\log |h|-\log \left|h_{3}\right|}{\log \left|h_{2}\right|-\log \left|h_{3}\right|} \quad h \in\left(h_{3}, h_{2}\right) \\
f_{s}(h)=0 \quad h \in\left(-\infty, h_{3}\right) \cup\left(h_{1},+\infty\right)
\end{array}
$$

On the basis of the experimental data presented by Williams et al. [1972], we selected the pressure head $h_{2}=-1.0 \mathrm{~m}$ for the optimal soil respiration; the pressure head $h_{3}$, when production ceases, is assigned the value $-10^{5} \mathrm{~m}$, and pressure head $h_{1}$ is equal to the air entry value, which is obtained from the retention curve.

\subsection{Production Dependence With Depth and Time}

In the following sections we use the exponential distribution (4) for both root and soil $\mathrm{CO}_{2}$ production rates as well as for the depth distribution of the root water uptake. We also set the time-dependent reduction coefficient, $f_{s}(t)$, to one for the soil microbial production. For plant root production of $\mathrm{CO}_{2}$, the reduction coefficient, $f_{p}(t)$, is calculated using the growth degree day concept, GDD, with the same constants as used for the root growth function. More detail about the time dependence of $\mathrm{CO}_{2}$ production and root depth development is available in paper 1.

\section{RIVERSIDE EXPERIMENT}

\subsection{Experimental Design}

Two $0.57 \mathrm{~m}$ diameter by $0.81 \mathrm{~m}$ deep open steel cylinders were installed in a $3.3 \times 5.0 \mathrm{~m}$ field plot of Pachappa fine sandy loam (mixed, thermic Mollic Haploxeralf) in River- 
side, California. The upper rim of each cylinder was flush with the soil surface. Next, slightly moist soil was packed in and around the cylinders and in two control sites where no cylinders were installed. Water was ponded on the plot to aid settling and subsequent surface leveling of the soil. Removable platforms were placed on the soil to minimize surface disturbance during sampling. Matric potential was determined using ceramic tensiometers inserted to a depth of 0.7 $\mathrm{m}$ in six locations. Aeration stones, connected to $0.02-\mathrm{m}$ diameter nylon tubing leading to the surface and capped with septum, were buried at $0.1,0.3,0.5$ and $0.7 \mathrm{~m}$ in the center of each site to sample soil air. The installation of air samplers, 2 days after the sites were packed, was designated as day zero of the experiment. Samplers at 1 and $1.5 \mathrm{~m}$ were also placed in the test area. On April 21 (day 5), sweet corn was seeded over the entire area, including three plants in each of the cylinders (plant density of 8.7 plants $\mathrm{m}^{-2}$ ). The plot surface was kept moist with daily overhead sprinkling until seedlings were established. The plot was flood irrigated approximately three times a week from day 23 to 132 . Air and soil temperature, crop height, soil matric potential, and soil air $\mathrm{CO}_{2}$ were monitored. Soil samples for water content were taken periodically. Soil air samples were obtained using plastic syringes with needles; $3 \mathrm{~mL}^{-1}$ of sample was withdrawn to flush the tubing, and then $3 \mathrm{~mL}^{-1}$ of gas was sampled. The samples were immediately injected into a gas chromatograph calibrated with standard $\mathrm{CO}_{2}$ gases to within $\pm 0.1 \mathrm{kPa} \mathrm{CO}$. Soil samples were analyzed for bulk density to evaluate soil uniformity and calculate porosity.

\subsection{Simulation Results and Discussion}

For the following simulations we use the model SOILCO2 [Šimunek and Suarez, this issue], which is intended to provide predictions of $\mathrm{CO}_{2}$ fluxes to the atmosphere and groundwater and $\mathrm{CO}_{2}$ concentration distributions in the soil with depth and time. The model includes transient onedimensional water flow and multiphase transport of $\mathrm{CO}_{2}$ utilizing the Richards and the convection-dispersion equations, respectively, as well as heat flow and a $\mathrm{CO}_{2}$ production submodel. The model SOILCO2 is described in detail in paper 1 .

The soil profile was considered homogeneous, with the parameters of the retention curve obtained by the nonlinear least squares curve-fitting program of van Genuchten [1978] using the data of Richards [1952]. The generated hydraulic parameters (Table 1) were utilized with the measured saturated hydraulic conductivity value of $0.25 \mathrm{~m} \mathrm{~d}^{-1}$ determined at the site (P. Shouse, personal communication, 1991). The depth of the root zone was calculated using the root growth model based on the logistic growth function and the degree day concept with $T_{B a s}=1470^{\circ} \mathrm{C}$ day [Gilmore and Rogers, 1958] and varied from zero (from day zero until seedling emergence on day 20) to $80 \mathrm{~cm}$ (harvest on day 116). Parameter $T_{B a s}$ reflects the heat units necessary for the plant to mature and roots to reach the maximum rooting depth. The parameters of the dimensionless water stress reduction function $\alpha_{s}(h)$ were taken as $h_{50}=-47 \mathrm{~m}$ [Maas, 1990] and $b=3$ [van Genuchten, 1987]. The normalized water uptake distribution function $\beta(z)$ was considered exponential with $a=10.5 \mathrm{~m}^{-1}$, i.e., in the absence of specific data we consider that about $65 \%$ of the root system is located in the upper $0.10 \mathrm{~m}$ of the soil (consistent with the findings of

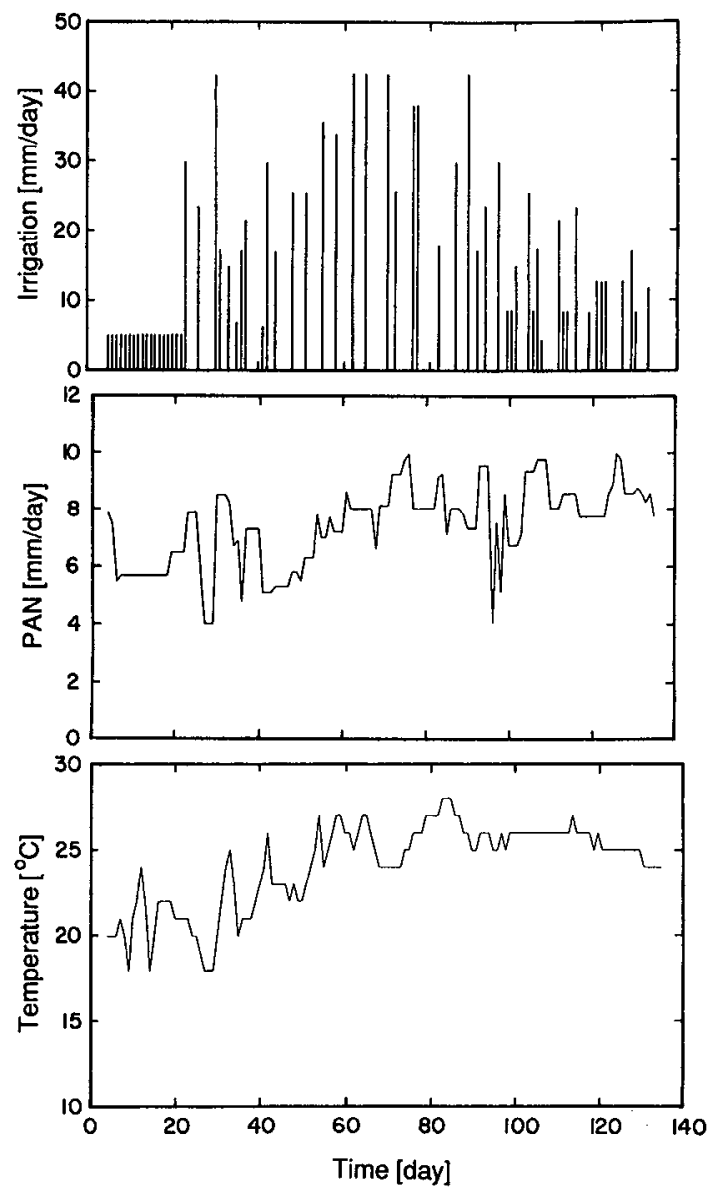

Fig. 12. Measured daily values of temperature, precipitation and pan evaporation, at Riverside, California, from April to September 1986.

Buyanovsky et al. [1986]). This distribution value was used for both soil and plant root respiration.

Shown in Figure 12 are the measured daily averages of irrigation or precipitation, pan evaporation and temperature. The potential evapotranspiration was estimated from evaporation data collected daily at the site with a class $A$ pan. The separation of potential transpiration and potential evaporation from potential evapotranspiration was done by using the mean crop coefficients for corn determined under similar climatic conditions at a comparable time of the year [Pruitt et al., 1987]. The initial pressure head at the start of the experiment was assumed constant at $-2.0 \mathrm{~m}$ over the whole profile. A constant pressure head of $-2.0 \mathrm{~m}$ was also considered as the lower boundary condition at the $5.0 \mathrm{~m}$ depth.

The initial volumetric $\mathrm{CO}_{2}$ concentration was constant at $1 \%$. The lower boundary condition for $\mathrm{CO}_{2}$ transport was zero flux. The upper boundary condition at the soil surface was constant $\mathrm{CO}_{2}$ concentration at the atmospheric value of $0.035 \%$.

The parameters for the thermal conductivity equation were taken from Chung and Horton [1987] for loam soil (Table 1). The measured air temperature was considered as the upper boundary condition with a daily amplitude of $5^{\circ} \mathrm{C}$. We set the temperature gradient to zero at the lower boundary. From the discussion above it follows that all parameters 


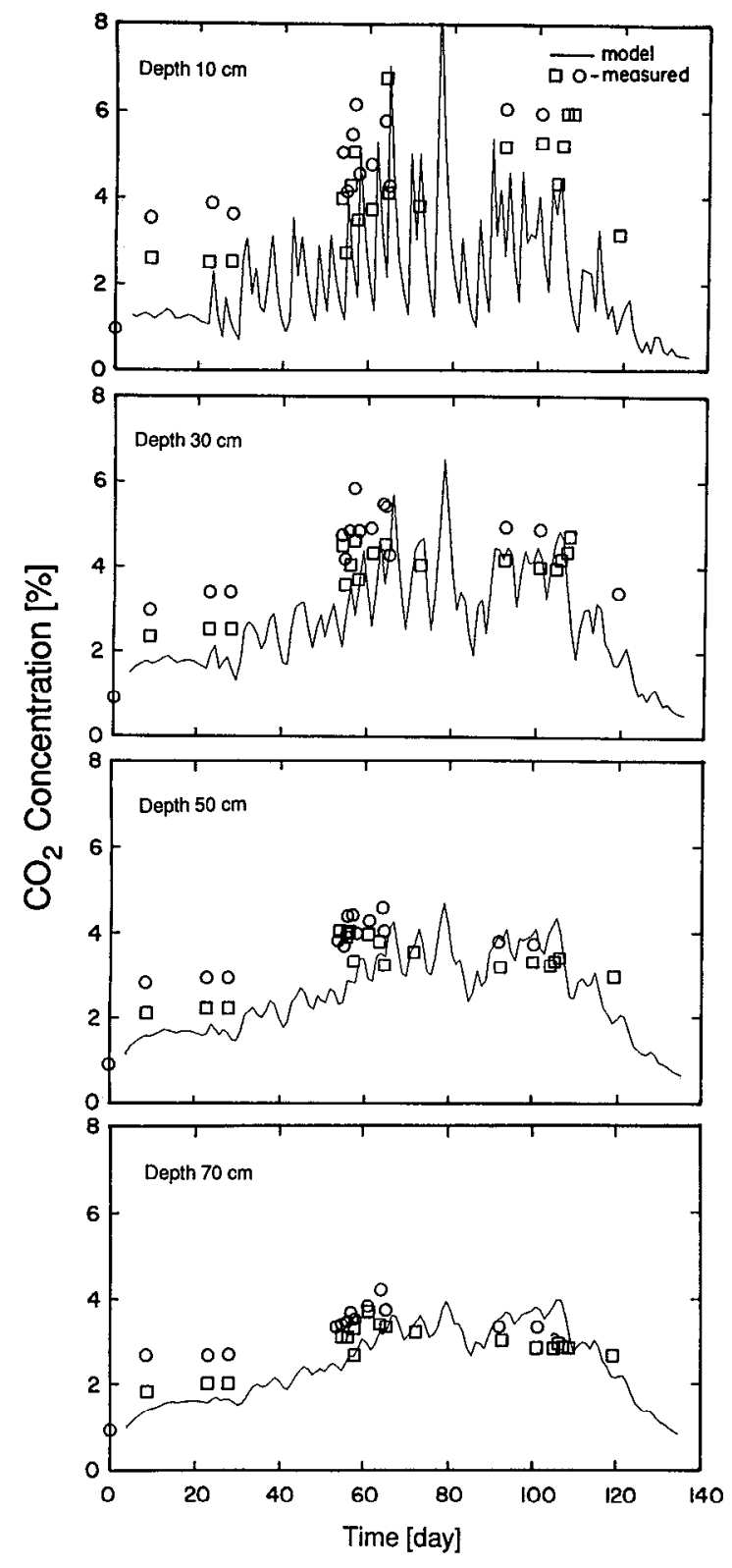

Fig. 13. Measured and calculated $\mathrm{CO}_{2}$ concentrations versus time at $0.10,0.30,0.50$ and $0.70 \mathrm{~m}$ soil depths for the Riverside, California, field experiment.

were either measured independently or adapted from the iiterature.

The simulaled and measured concentrations of $\mathrm{CO}_{2}$ for individual depths are presented in Figure 13. There is a very large fluctuation in $\mathrm{CO}_{2}$ concentrations at the depths closest to the soil surface, with smaller fluctuations in deeper horizons. These fluctuations reflect the irrigation plan. After each irrigation there is an increase in $\mathrm{CO}_{2}$ concentrations due to the reduced flux of $\mathrm{CO}_{2}$ to the atmosphere, which is caused by higher water content at the soil surface and a corresponding decrease in the local diffusion coefficient and tortuosity factor. With the drying of the surface layer there is a corresponding decrease in $\mathrm{CO}_{2}$ concentration in the soil profile.

The simulated $\mathrm{CO}_{2}$ concentrations model the measured data relatively well except for the beginning of the experi- ment where the $\mathrm{CO}_{2}$ concentrations are underestimated at all depths. In contrast to the model simulation and extensive data reported in the literature, the measured concentrations show relatively high values at the start of the experiment and only a doubling of concentration with time. At the beginning of the experiment the initially dry soil was moistened and placed in the control sites. This sudden wetting of the soil can cause high production of $\mathrm{CO}_{2}$ for up to several weeks [Das, 1970] and can explain the differences between the measured and simulated values for the first 30 days. Similarly, after the plants were removed from the field there was somewhat higher production of $\mathrm{CO}_{2}$ than predicted. Apparently the decomposition of dead roots resulted in higher $\mathrm{CO}_{2}$ concentrations than simulated. This process can be simulated by using a time-dependent function for the microbial production of $\mathrm{CO}_{2}$. Most published data sets consider environments where the crop harvest corresponds with a decreasing temperature; thus microbial decomposition of roots may not occur until the following spring. In contrast, high soil temperatures and optimal water content remained after harvesting in our expcriment.

The calculated $\mathrm{CO}_{2}$ production was about $0.004 \mathrm{~m}^{3} \mathrm{~m}^{-2}$ $\mathrm{d}^{-1}$ in the spring when the air temperature was around $20^{\circ} \mathrm{C}$ and root development and thus plant respiration were negligible. The calculated production increased to about $0.010 \mathrm{~m}^{3}$ $\mathrm{m}^{-2} \mathrm{~d}^{-1}$ in the summer, when the air temperature was around $26^{\circ} \mathrm{C}$ and plant development was at its maximum. Calculated production decreased at the end of the crop growth cycle.

The cumulative values for both $\mathrm{CO}_{2}$ production and flux to the atmosphere are shown in Figure 14. The difference between the two curves shown in Figure 14 is the amount of $\mathrm{CO}_{2}$ produced that is either stored in the soil zonc or recharged to the subsurface with the drainage water. The close correspondence between the curves indicates that flux measurements can adequately represent production within large time intervals, (weeks to months) and that changes in $\mathrm{CO}_{2}$ storage and recharge are not a large component of the total production. It is evident that most $\mathrm{CO}_{2}$ produced in the soil almost immediately escapes into the atmosphere. Therefore, the comparison of the measured and calculated $\mathrm{CO}_{2}$ concentrations in the soil profile does not provide a complete validation of the SOILCO2 model. It is possible, for exam-

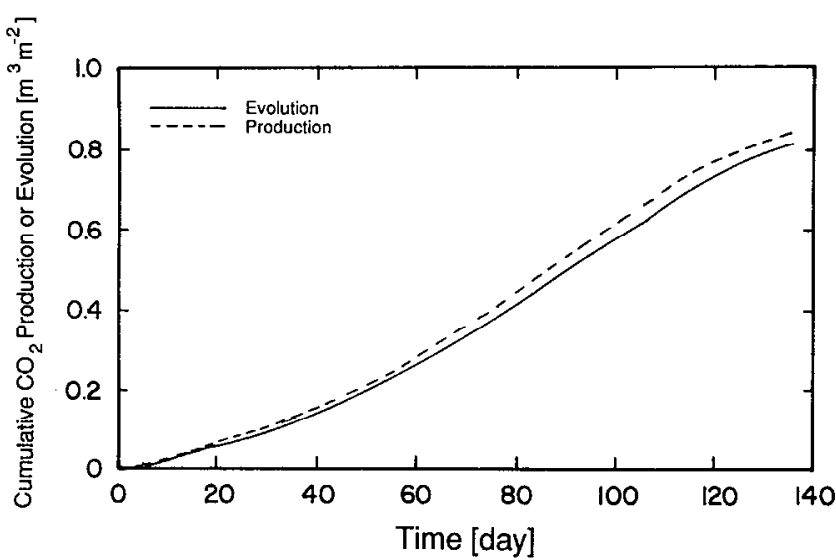

Fig. 14. Cumulative $\mathrm{CO}_{2}$ production in the soil profile and $\mathrm{CO}_{2}$ flux to the atmosphere for the Riverside, California, field experiment. 
ple, to underestimate production and flux and achieve a good fit with measured soil profile $\mathrm{CO}_{2}$ concentrations if the tortuosity is overestimated. Therefore in the following seclion we use a more comprehensive data set published by Buyanovsky and Wagner [1983] and Buyanovsky et al. [1986], which provides both measured soil profile $\mathrm{CO}_{2}$ concentrations and measured $\mathrm{CO}_{2}$ fluxes to the atmosphere for several crops.

\section{MisSOURI EXPERIMENT}

The predictive capabilities of SOILCO2 were further evaluated by comparing simulations to the field data published by Buyanovsky and Wagner [1983] and Buyanovsky et al. [1986] for wheat, soybeans and corn grown in Missouri. Buyanovsky and Wagner [1983] presented data for part of the year 1981 and all of the year 1982 on $\mathrm{CO}_{2}$ dynamics in soil under three different cropping systems and discussed these data with regard to crop effects, microbial activity, and relevant abiotic factors including soil water content and lemperature. In the second paper, Buyanovsky et al. [1986] investigated annual cycles (1981-1983) of $\mathrm{CO}_{2}$ evolution into the atmosphere from a soil cultivated to wheat and related the $\mathrm{CO}_{2}$ flux to plant development, as well as to the effect of temperature and water content. Since it was our objective to compare the $\mathrm{CO}_{2}$ concentrations in the soil as well as the simulated and measured $\mathrm{CO}_{2}$ evolution from the soil, we first generated a prediction for the year 1982 for the soil cultivated to wheat. We initiated the simulation at the beginning of March (the first month with positive air temperatures) and terminated it at the end of October. Buyanovsky and Wagner [1983] presented data for daily precipitation and average weekly air temperatures, as well as $\mathrm{CO}_{2}$ concentrations in the soil air, soil water content and soil temperature at the 20 $\mathrm{cm}$ depth. From the air temperatures we calculated values of potential evapotranspiration using Thornthwaite's formula [de Marsily, 1986]. Buyanovsky and Wagner [1983] reported the textural characteristics of their Mexico silt loam as well as organic matter content, bulk density, and air porosity at field capacity. After inspection of these data we divided the soil profile into three horizons: A, B1 and B2. Since we did not have the hydraulic characteristics of this soil we used the mean textural characteristics and the linear regression equations reported by Rawls et al. [1982] to obtain the soil water contents at 10 different soil water pressure heads. These data

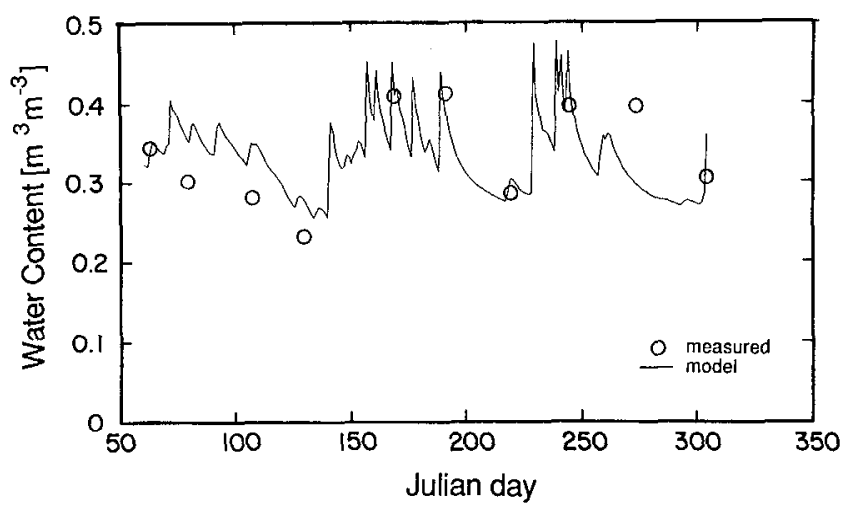

Fig. 15. Measured [Buyanovsky and Wagner, 1983] and calculated water contents at a depth of $0.20 \mathrm{~m}$ for the Missouri wheat experiment, 1982.

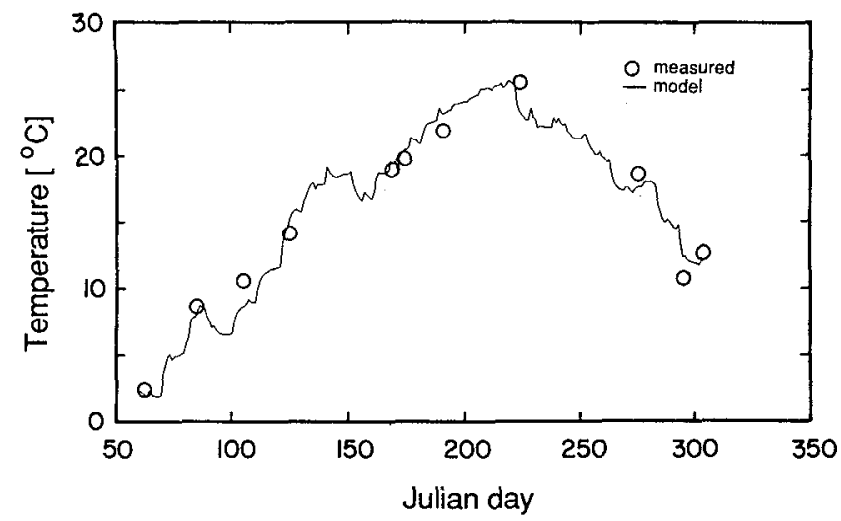

Fig. 16. Measured [Buy.znovsky and Wagner, 1983] and calculated temperatures at a depth of $0.20 \mathrm{~m}$ for the Missouri wheat experiment, 1982 .

were then used to determine regression parameters of the retention equation by nonlinear least squares curve fitting [van Genuchten, 1978]. The calculated retention curves were scaled in order to insure that they correspond to the porosity calculated from the data on bulk density and specific density and to the measured air porosity at field capacity [Buyanovsky and Wagner, 1983].

The depth of the root zone as a function of time was again calculated with the root growth model as developed by Simunek and Suarez [this issue] with $T_{B a s}=1275^{\circ} \mathrm{C}$ day (base temperature of $4.4^{\circ} \mathrm{C}$ ) calculated from Pirasteh and Welsh [1980]. The wheat was planted in the middle of October 1981; therefore we assigned the root depth at the beginning of the simulation on March 1 to be $5 \mathrm{~cm}$. The wheat was harvested around July 10 . We also assumed (as in the Riverside experiment) that $65 \%$ of the roots are in the top $0.1 \mathrm{~m}$, which leads to the coefficient $a=10.5 \mathrm{~m}^{-1}$ for the exponential root distribution. The root depth distribution selected is consistent with the observations of Buyanovsky et al. [1986] that about $50 \%$ of the roots were located in the upper $0.1 \mathrm{~m}$ layer during the early stage of crop development, whereas in the later stages up to $75-80 \%$ of the roots were in this layer.

A relatively wet soil profile with a constant pressure head of $-1.0 \mathrm{~m}$ was used as the initial condition. The lower boundary condition was taken as free drainage at a depth of $1.6 \mathrm{~m}$. Figure 15 shows the water content at a depth of $0.2 \mathrm{~m}$ as reported by Buyanovsky and Wagner [1983] and as predicted by the model. The correspondence of measured and calculated values is quite good in view of the relatively inaccurate methods used for estimation of the hydraulic characteristics and potential evapotranspiration (because of the lack of available data).

Since the Mexico silt loam has a high clay content (from 22 to 53\%), we used the parameters for the thermal conductivity from Chung and Horton [1987] for clay (Table 1). The measured air temperature was taken as the upper boundary condition with a daily amplitude of $5^{\circ} \mathrm{C}$. A zero temperature gradient was used as the lower boundary condition. The measured and calculated temperatures at the $0.2 \mathrm{~m}$ depth are shown in Figure 16. There is an excellent correspondence betwcen measured and calculated values, which is important since temperature has a significant effect on $\mathrm{CO}_{2}$ production. Unfortunately, experimental data were not available for 


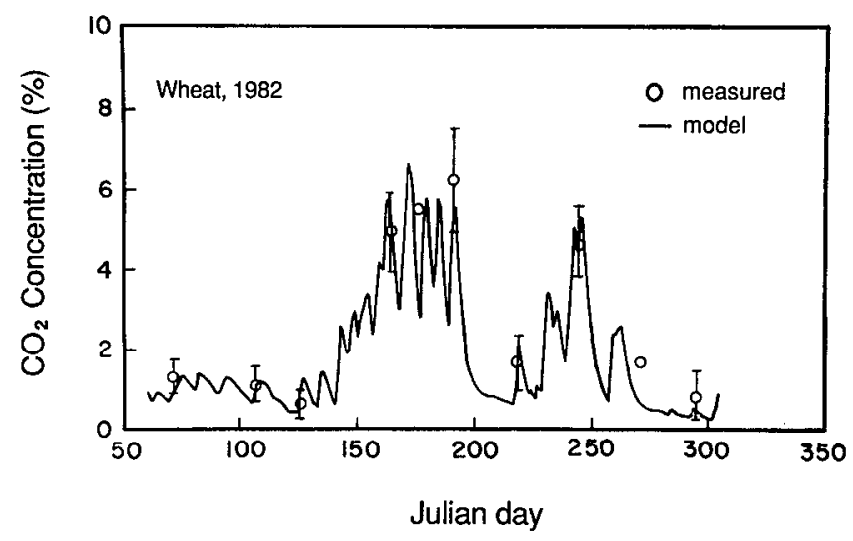

Fig. 17. Measured [Buyanovsky and Wagner, 1983] and calculated $\mathrm{CO}_{2}$ concentrations at a depth of $0.20 \mathrm{~m}$ for the Missouri wheat experiment, 1982. Vertical bars show standard deviations.

deeper depths, which would be required for a more rigorous test of the heat transport submodel.

All the initial and boundary conditions for $\mathrm{CO}_{2}$ transport, as well as the $\mathrm{CO}_{2}$ production and reduction coefficients, were the same as used for the Riverside experiment. Figure 17 shows an excellent agreement between measured and calculated $\mathrm{CO}_{2}$ concentrations at the $0.2 \mathrm{~m}$ depth. In all instances the calculated values are within one standard deviation of the mean of the measured values. There are no statistically significant differences between the measured and predicted $\mathrm{CO}_{2}$ concentrations at the $90 \%$ confidence level. The irregular pattern of the $\mathrm{CO}_{2}$ concentrations shown in Figure 17 reflects the fact that within the dry periods (first half of May, second half of July and all of October), the $\mathrm{CO}_{2}$ concentrations decrease to very low values, while during the wet periods the $\mathrm{CO}_{2}$ concentrations are relatively high. As with the Riverside data, we observe fluctuations in the $\mathrm{CO}_{2}$ concentration that are dependent on the precipitation pattern or soil water content in the upper horizon.

Figure 18 shows the comparison of the calculated daily and weekly $\mathrm{CO}_{2}$ fluxes to the atmosphere with the flux measurements of Buyanovsky et al. [1986]. We present the weekly values in addition to the daily values, since these rates fluctuate

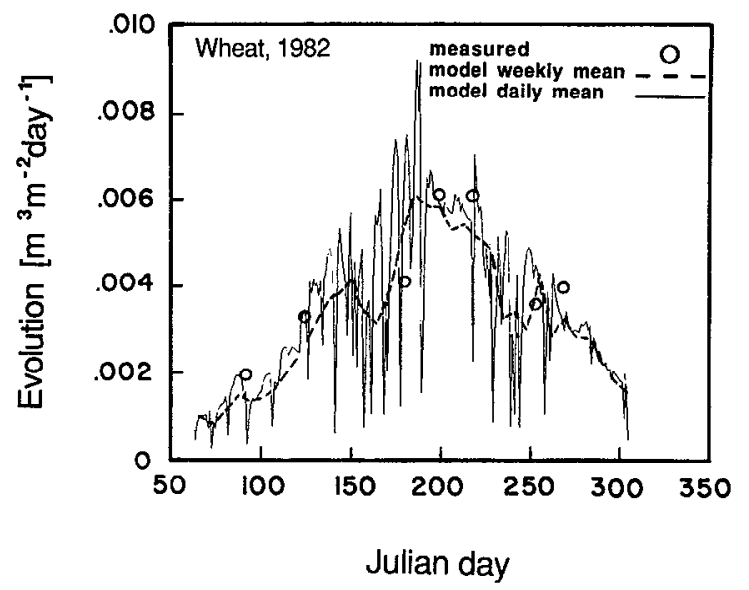

Fig. 18. Measured [Buyanovsky et al., 1986] and calculated daily and weckly $\mathrm{CO}_{2}$ flux to the atmosphere for the Missouri wheat experiment, 1982.

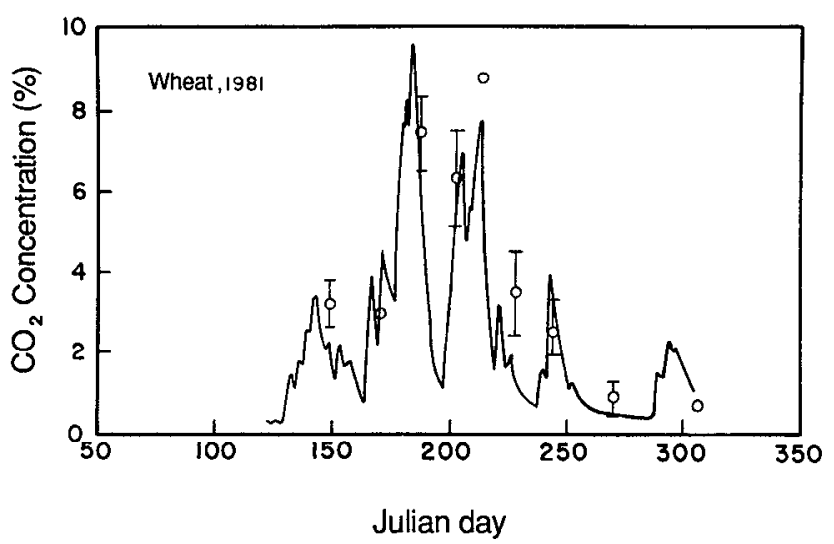

Fig. 19. Measured [Buyanovsky and Wagner, 1983] and calculated $\mathrm{CO}_{2}$ concentrations at a depth of $0.20 \mathrm{~m}$ for the Missouri wheat experiment, 1981. Vertical bars show standard deviations.

significantly on a daily basis corresponding to changes in the water status of the upper layer. The calculations provided daily changes of similar magnitude as those simulated at the Riverside site. The large fluctuations shown in Figure 18 indicate that the accurate determination of flux requires an excessive number of measurements if the surface water content is rapidly changing, as occurs with frequent water applications. As with the $\mathrm{CO}_{2}$ concentration data, there is an excellent correspondence between measured and calculated flux values.

Additional data are available from Buyanovsky and Wagner [1983] and Buyanovsky et al. [1986] for $\mathrm{CO}_{2}$ concentrations and surface fluxes for wheat grown in 1981. Although the data are available for only part of the growing season (data collection started in May 1981), we nonetheless can compare our model predictions to the partial data set. All the model parameters (hydraulic, gas diffusion, production function, etc.) are the same as used in the 1982 wheat simulation. As shown in Figure 19 for the available data at the $20 \mathrm{~cm}$ depth, the model represents the data relatively well, in both the absolute concentration and the response to changes in environmental factors such as water content and temperature. Comparison of the measured and model predicted flux, shown in Figure 20, shows that the model provided a

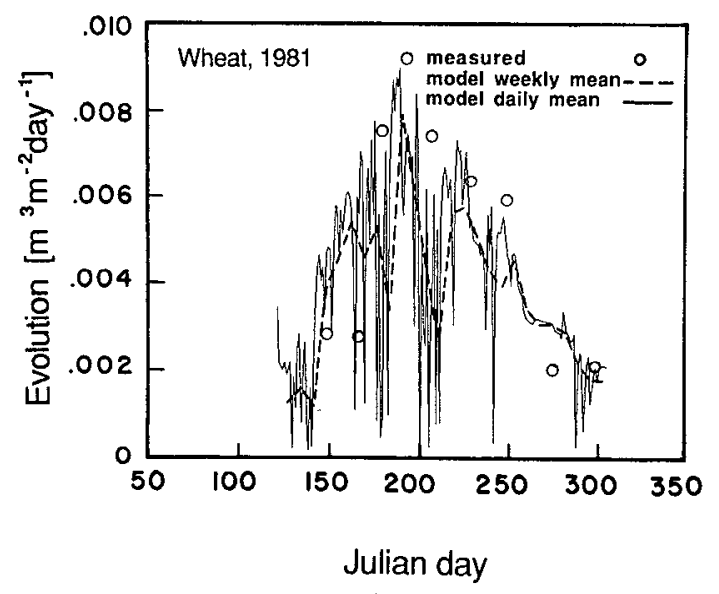

Fig. 20. Measured [Buyanovsky et al., 1986] and calculated daily and weckly $\mathrm{CO}_{2}$ flux to the atmosphere for the Missouri wheat experiment, 1981. 


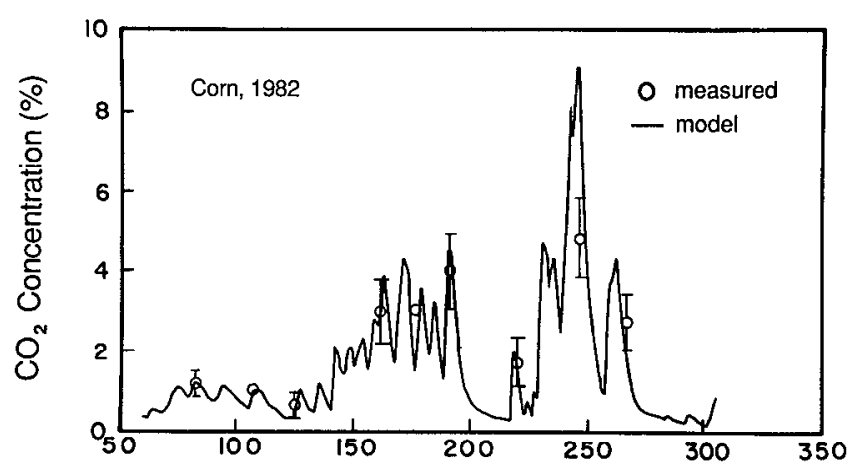

Julian day

Fig. 21. Measured [Buyanovsky and Wagner, 1983] and calculated $\mathrm{CO}_{2}$ concentrations at a depth of $0.20 \mathrm{~m}$ for the Missouri corn experiment, 1982. Vertical bars show standard deviations.

relatively good fit with some underestimation during the interval of highest flux. The large fluctuations in daily flux are primarily due to rapid decreases in flux immediately after a rain event.

Further evaluation of the model is possible using $\mathrm{CO}_{2}$ concentration measurements made by Buyanovsky and Wagner [1983] for corn and soybeans grown in 1982. The $\mathrm{CO}_{2}$ concentrations and flux in the field planted to corn were simulated with the SOILCO2 model utilizing the same parameters as used for wheat except for the following: We utilized the planting and harvest dates of day 125 and 265, respectively, listed by Buyanovsky and Wagner [1983] and used the degree day value of 1470 for corn (base temperature of $10^{\circ} \mathrm{C}$ ) as determined by Gilmore and Rogers [1958]. As shown in Figure 21 there was a very good correspondence between the measured and predicted values. In addition, the higher soil $\mathrm{CO}_{2}$ concentrations determined for the wheat as compared to the corn experiment, for the interval around day $140-190$, is also predicted by the model. These differences are due primarily to the earlier planting date for wheat as compared to corn.

The $\mathrm{CO}_{2}$ concentration measurements made by $B u y-$ anovsky and Wagner [1983] for soybeans grown in 1982 were simulated with the same model parameters as used for corn except the planting and harvest dates were given by them as day 160 and 295, respectively. In the absence of specific information on soybeans we utilized the degree day value of 1470 used for corn. The data shown in Figure 22 again show an excellent correspondence between predicted and measured values. The similarities between Figure 21 and Figure 22 may indicate that crop differences may be minor for crops that can be grown at the same location, and planted and harvested at approximately the same time.

\section{Summary and Conclusion}

In this study we presented a sensitivity analysis of the factors controlling $\mathrm{CO}_{2}$ concentration in soils using simulations with the SOILCO2 model reported earlier [Šmunek and Suarez, this issue] which considers water flow, heat transport and $\mathrm{CO}_{2}$ production and transport in a variably saturated porous media. The effects of several factors such as water pressure head, depth, temperature, $\mathrm{CO}_{2}$ concentration and time on $\mathrm{CO}_{2}$ concentrations were considered. Heat

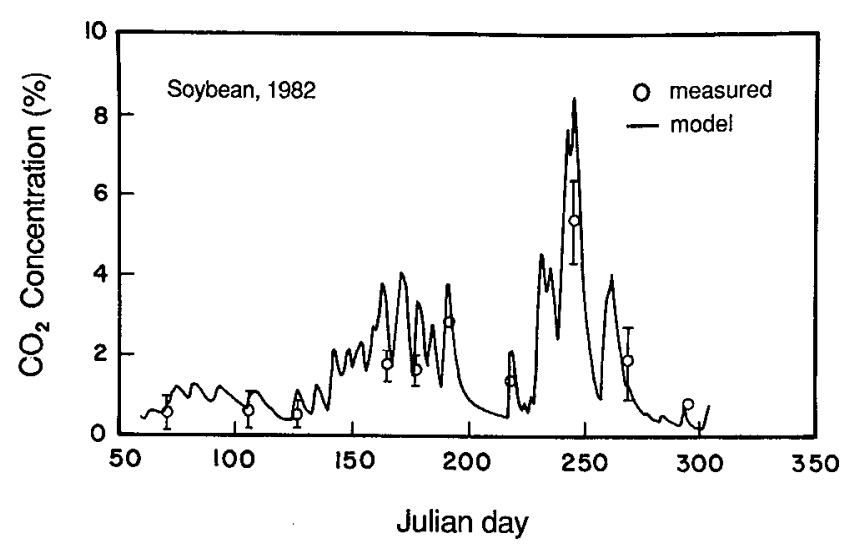

Fig. 22. Measured [Buyanovsky and Wagner, 1983] and calculated $\mathrm{CO}_{2}$ concentrations at a depth of $0.20 \mathrm{~m}$ for the Missouri soybean experiment, 1982. Vertical bars show standard deviations.

transport was included since the transport, partition and production parameters of $\mathrm{CO}_{2}$ are strongly temperaturc dependent.

The most difficult aspect in modeling $\mathrm{CO}_{2}$ concentration and transport is obtaining an adequate description of water movement, since changes in water content significantly influence the diffusive transport of $\mathrm{CO}_{2}$. The model was able to adequately simulate the $\mathrm{CO}_{2}$ concentration with depth and time for a field experiment with corn conducted in Riverside, California, at relatively constant water contents and for high-frequency irrigation. In addition, the model provided an excellent simulation of the data of Buyanovsky and Wagner [1983] and Buyanovsky et al. [1986] both for $\mathrm{CO}_{2}$ concentration with time and depth for ficlds cropped to wheat, corn and soybeans in Missouri, and for the available data for $\mathrm{CO}_{2}$ flux to the atmosphere. The agreement between the model predictions and the data, for both the concentration and flux values, indicates that the SOILCO2 model not only can provide an acceptable prediction of these values, but that the model is likely properly simulating the diffusion process.

The SOILCO2 model will be used for the calculation of $\mathrm{CO}_{2}$ transport and production in an unsaturated soil and with recharge to the groundwater, for estimating the rate at which $\mathrm{CO}_{2}$ leaves the soil environment at the soil surface, and as an input to solute transport-chemistry models to simulate unsaturated zone chemistry including inorganic carbon sequestration in the root zone. Further field studies will be conducted to gain a better understanding of $\mathrm{CO}_{2}$ production, particularly at the start of the growing season and at the end when root decay is potentially most rapid (assuming adequate temperature).

\section{Notation}

a parameter in the exponential depth reduction function $\left[L^{-1}\right]$.

$b$ empirical constant in the water stress response function [dimensionless].

$b_{1}, b_{2}, b_{3}$ parameters of the thermal conductivity function $\left[W L^{-1} K^{-1}\right]$.

$c_{a} \quad \mathrm{CO}_{2}$ concentration in the gas phase $\left[L^{3} L^{-3}\right]$.

$D_{E}$ effective dispersion coefficient in the soil matrix $\left[L^{2} T^{-1}\right]$. 
$E$ activation energy of the reaction $\left[M L^{2} T^{-2} n^{-1}\right]$.

EC electric conductivity $\left[S L^{-1}\right]$.

$f_{p}$ reduction function for $\mathrm{CO}_{2}$ production by plant roots [dimensionless].

$f_{s}$ reduction function for $\mathrm{CO}_{2}$ production by soil microorganisms [dimensionless].

$h$ water pressure head $[L]$.

$h_{2}$ pressure head when $\mathrm{CO}_{2}$ production is optimal $[L]$.

$h_{1}, h_{3}$ pressure head when $\mathrm{CO}_{2}$ production ceases $[L]$.

$h_{50}, h_{\phi 50}$ empirical constant in the water or osmotic stress response functions, respectively $[L]$.

$h_{\phi}$ osmotic head $[L]$.

$K_{H}$ Henry's law constant $\left[n T^{2} M^{-1} L^{-2}\right]$.

$K_{M}^{*}$ Michaelis constant for $\mathrm{CO}_{2}$ concentration $\left[L^{3} L^{-3}\right]$.

$K_{S} \quad$ saturated hydraulic conductivity $\left[L T^{-1}\right]$.

$n$ parameter of the retention curve [dimensionless].

$q_{E} \quad \mathrm{CO}_{2}$ effective velocity $\left[L T^{-1}\right]$

$Q_{10}$ coefficient representing the relative increase in respiration intensity per $10^{\circ} \mathrm{C}$ increase in temperature [dimensionless].

$R$ universal gas constant $\left[M L^{2} T^{-2} K^{-1} n^{-1}\right]$.

$S$ production/sink term for $\mathrm{CO}_{2}\left[L^{3} L^{-3} T^{-1}\right]$.

$T$ temperature [K].

$t$ time $[T]$.

$T_{B a s}$ heat units necessary for the plant to mature and roots to reach the maximum rooting depth [KT].

$z \quad$ spatial coordinate (positive downward) $[L]$.

$\alpha$ parameter of retention curve $\left[L^{-1}\right]$.

$\alpha_{s}, \alpha_{\phi}$ dimensionless water and osmotic stress response functions, respectively.

$\beta$ normalized water uptake distribution function $\left[L^{-1}\right]$.

$\gamma_{0}$ optimal $\mathrm{CO}_{2}$ production $\left[L^{3} L^{-2} T^{-1}\right]$.

$\gamma_{p}, \gamma_{s}$ actual production by plant roots and soil microorganisms, respectively $\left[L^{3} L^{-3} T^{-1}\right]$.

$\gamma_{p 0}, \gamma_{s 0}$ optimal production by plant roots and soil microorganisms, respectively $\left[L^{3} L^{-2} T^{-1}\right]$.

$\phi$ osmotic pressure (pascals).

$\theta_{a}, \theta_{w}$ volumetric air and water contents, respectively $\left[L^{3} L^{-3}\right]$.

$\theta_{r}, \theta_{s}$ residual and saturated volumetric water contents, respectively $\left[L^{3} L^{-3}\right]$.

\section{REFERENCES}

Amundson, R. G., and V. S. Smith, Annual cycles of physical and biological properties in an uncultivated and irrigated soil in the San Joaquin Valley of California, Agric. Ecosyst. Environ., 20, 195-208, 1988

Anderson, J. M., Carbon dioxide evolution from two temperate, deciduous woods and soils, J. Appl. Ecol., 10, 361-378, 1973.

Armstrong, W., and T. J. Gaynard, The critical oxygen pressures for respiration in intact plant, Physiol. Plant, 37, 200-206, 1976.

Buyanovsky, G. A., and G. H. Wagner, Annual cycles of carbon dioxide level in soil air, Soil Sci. Soc. Am.J., 47, 1139-1145, 1983.

Buyanovsky, G. A., G. H. Wagner, and C. J. Gantzer, Soil respiration in a winter wheat ecosystem, Soil Sci. Soc. Am.J., 50, 338-344, 1986.

Carey, R. W., and J. A. Berry, Effects of low temperature on respiration and uptake of rubidium ions by excised barley and corn roots, Plant Physiol., 61, 858-860, 1978.
Chung, S.-O., and R. Horton, Soil heat and water flow with a partial surface mulch, Water Resour. Res., 23(12), 2175-2186, 1987.

Currie, J. A., Soil respiration, Tech. Bull. Minist. Agric. Fish. Food G. B., 29, 461 pp., 1975.

Das, A. C., Carbon dioxide evolution from soils, I, A preliminary study, Technology, 7, 252-254, 1970.

de Jong, E., and H. J. V. Schappert, Calculation of soil respiration and activity from $\mathrm{CO}_{2}$ profiles in the soil, Soil Sci., 113, 328-333, 1972.

de Marsily, G., Quantitative Hydrology: Groundwater Hydrology for Engineers, Academic, San Diego, Calif., 1986.

Edwards, N. T., and P. Sollins, Continuous measurement of carbon dioxide evolution from partitioned forest floor components, $E \mathrm{col}$ ogy, 54, 406-412, 1973.

Gilmore, E. C., and J. S. Rogers, Heat units as a method of measuring maturity in corn, Agron. J., 50, 611-615, 1958.

Glinski, J., and W. Stepniewski, Soil Aeration and Its Role for Plants, CRC Press, Boca Raton, Fla., 1985.

Gunn, J., and S. T. Trudgill, Carbon dioxide production and concentrations in the soil atmosphere: A case study from New Zealand volcanic soils, Catena, 9, 81-94, 1982.

Harned, H. S., and R. Davis, Jr., The ionization constant of carbonic acid and the solubility of carbon dioxide in water and aqueous salt solutions from 0 to $50^{\circ} \mathrm{C}, J$. Am. Chem. Soc., 653, 2030-2037, 1943.

Hillel, D., and C. H. M. van Bavel, Simulation of profile water storage as related to soil hydrologic properties, Soil Sci. Soc. Am. J., 40, 807-815, 1976.

Holt, J. A., M. J. Hodgen, and D. Lamb, Soil respiration in the seasonally dry tropics near Townsville, north Queensland, Aust. J. Soil Res., 28, 737-745, 1990.

Howard, P. J. A., and D. M. Howard, Respiration of decomposing litter in relation to temperature and moisture, 2, Microbial decomposition of tree and shrub leaf litter, Oikos, 33, 457-465, 1979.

Jurinak, J. J., and D. L. Suarez, The chemistry of salt-affected soils and waters, in Agricultural Salinity Assessment and Management, ASCE Man, and Rep. on Eng., vol. 71, edited by K. K. Tanji, chap. 3, pp. 42-63, American Society of Civil Engineers, New York, 1990.

Kiefer, R. H., Soil carbon dioxide concentrations and climate in a humid subtropical environment, Prof. Geogr., 4, 182-194, 1990.

Kucera, C. L., and D. R. Kirkham, Soil respiration studies in tallgrass prairie in Missouri, Ecology, 52, 912-915, 1971.

Lundegard, H., Carbon dioxide evolution of soil and crop growth, Soil Sci., 23, 417-454, 1927.

Luxmoore, R. J., L. H. Stolzy, and J. Letey, Oxygen diffusion in the soil plant system, I, A model, Agron. J., 62, 317-321, 1970.

Maas, E. V., Crop salt tolerance, in Agricultural Salinity Assessment and Management, ASCE Man. and Rep. on Eng., vol. 71, edited by K. K. Tanji, chap. 13, pp. 262-304, American Society of Civil Engineers, New York, 1990.

Monteith, J. L., G. Szeicz, and E. A. Paul, Crop photosynthesis and the flux of carbon dioxide below the canopy, J. Appl. Ecol., 6, $321-337,1964$.

Pirasteh, B., and J. R. Welsh, Effect of temperature on the heading date of wheat cultivars under a lengthening photoperiod, Crop Sci., 20, 453-456, 1980.

Pruitt, W. O., E. Fereres, K. Kaita, and R. L. Snyder, Reference evapotranspiration $\left(\mathrm{ET}_{0}\right)$ for California, Agric. Exp. Sta. Bull. 1922, 16 pp., Univ. of Calif., Berkeley, 1987.

Raats, P. A. C., Steady flows of water and salt in uniform soil profiles with plant roots, Soil Sci. Soc. Am. Proc., 38, 717-722, 1974.

Rawls, W. J., D. L. Brakensiek, and K. E. Saxton, Estimation of soil water properties, Trans. ASAE, 25, 1316-1320, 1982.

Richards, L. A., Water conducting and retaining properties of soils in relation to irrigation, paper presented at International Symposium on Desert Research, U.N. Educ., Sci., and Cult. Organ., Jerusalem, 1952.

Rixon, A. J., and B. J. Bridge, Respiratory quotient arising from microbial activity in relation to matric suction and air filled pore space of soil, Nature, 218, 961-962, 1968.

Ross, D. J., and A. Cairns, Influence of temperature on biochemical processes in some soils from tussock grasslands, 1, Respiratory activity, N. Z. J. Sci., 21, 581-589, 1978.

Simunek, J., and D. L. Suarez, Modeling of carbon dioxide trans- 
port and production in soil, 1, Model development, Water Resour. Res., this issue.

Solomon, D. K., and T. E. Cerling, The annual carbon dioxide cycle in a Montane soil: Observation, modeling, and implication for weathering, Water Resour. Res., 23(12), 2257-2265, 1987.

van Genuchten, M. T., Calculating the unsaturated hydraulic conductivity with a new closed-form analytical model, Rep. 78-WR08, Water Resour. Program, Princeton Univ., Princeton, N. J. 1978.

van Genuchten, M. T., A numerical model for water and solute movement in and below the root zone, research report, U.S. Salin. Lab., Agric. Res. Serv., U.S. Dep. of Agric., Riverside, Calif., 1987.

Williams, S. T., M. Shameemullah, E. T. Watson, and C. I. Mayfield, Studies on the ecology of actinomycetes in soil, IV, The influence of moisture tension on growth and survival, Soil Biol. Biochem., 4, 215-225, 1972.

Witkamp, M., Cycles of temperature and carbon dioxide evolution from litter and soil, Ecology, 50, 922-924, 1969.

J. Simůnek and D. L. Suarez, U.S. Salinity Laboratory, Agricultural Research Service, U.S. Department of Agriculture, 4500 Glenwood Drive, Riverside, CA 92501.

(Received April 13, 1992;

revised September 3, 1992;

accepted September 16, 1992.) 